\title{
Is Processing of Symbols and Words Influenced by Writing System? Evidence from Chinese, Korean, English, and Greek
}

\author{
Angeliki Altani and George K. Georgiou \\ University of Alberta \\ Ciping Deng \\ East China Normal University \\ Jeung-Ryeul Cho \\ Kyungnam University \\ Katerina Katopodi \\ National and Kapodistrian University of Athens \\ Wei Wei \\ Shanghai Normal University \\ Athanassios Protopapas* \\ National and Kapodistrian University of Athens and University of Oslo
}

In press, Journal of Experimental Child Psychology

* Correspondence: Athanassios Protopapas, Department of Special Needs Education, University of Oslo, PO Box 1140, Blindern, 0318 Oslo, Norway; email: athanasios.protopapas@isp.uio.no 


\begin{abstract}
We examined cross-linguistic effects in the relationship between serial and discrete versions of digit naming and word reading. One hundred thirteen Mandarin-speaking Chinese, 100 Korean, 112 English-speaking Canadian, and 108 Greek Grade 3 children were administered tasks of serial and discrete naming of words and digits. Interrelations among tasks indicated that the link between rapid naming and reading is largely determined by the format of the tasks across orthographies. Multigroup path analyses with discrete and serial word reading as dependent variables revealed commonalities as well as significant differences between writing systems. The path coefficient from discrete digits to discrete words was greater for the more transparent orthographies, consistent with more efficient sight-word processing. The effect of discrete word reading on serial word reading was stronger in alphabetic languages, in which there was also a suppressive effect of discrete digit naming. However, the effect of serial digit naming on serial word reading did not differ between the four language groups. This pattern of relationships challenges a universal account of reading fluency acquisition while upholding a universal role of rapid serial naming, further distinguishing between multi-element inter-word and intra-word processing.
\end{abstract}

Keywords: Cross-linguistic; rapid automatized naming; reading; fluency; writing systems; orthography. 


\section{Is Processing of Symbols and Words Influenced by Writing System? Evidence from Chinese, Korean, English, and Greek}

Rapid automatized naming (RAN) is a strong predictor of reading fluency across orthographies (e.g., Cho \& Chiu, 2015; de Jong, 2011; Georgiou, Aro, Liao, \& Parrila, 2016; Moll, Fussenegger, Willburger, \& Landerl, 2009; Parrila, Kirby, \& McQuarrie, 2004; Wei, Georgiou, \& Deng, 2015). Researchers have argued that the relationship between RAN and reading can reveal important information on how words are processed and, most importantly, how reading fluency is achieved, drawing a distinction between serial and discrete naming and how they relate to word reading (e.g., de Jong, 2011; Protopapas, Altani, \& Georgiou, 2013a). In serial naming (i.e., RAN), items are presented simultaneously on a grid and the participant must process them sequentially, traversing the grid at an endogenously controlled rate. In contrast, in discrete naming, items are presented individually on the screen for participants to name and then wait for the next item to appear.

\section{Differential Associations With Serial and Discrete Naming}

The serial format produces shorter total naming times than discrete naming, that is, a serial advantage is observed, at least for typical readers (Zoccolotti et al., 2013). In addition, it has long been noted that reading fluency correlates more strongly with serial naming than with discrete naming (Wolf \& Bowers, 1999); this serial superiority effect has been recently confirmed across languages, for readers past the beginner stage (e.g., de Jong, 2011; Protopapas et al., 2013a; van den Boer, Georgiou, \& de Jong, 2016). The crucial distinction between serial and discrete naming is thought to concern sequential processing, that is, skill in the serial processing of successive stimuli. In other words, serial naming requires all processes involved in discrete naming and also serial scanning of the array and rapid processing of multiple stimuli in 
the order they are displayed. Therefore, discrete naming can assess the efficiency of verbal responses to unitary visual stimuli, whereas RAN can be used as a measure of serial processing skill, over and above discrete naming. Consequently, correlations with RAN, controlling for discrete naming, can be used as indices of serial processing. Alternative explanations of the serial superiority effect invoking effects of executive function or visual scanning direction have failed to account for the observed associations (Altani, Protopapas, \& Georgiou, 2017; Protopapas, Altani, \& Georgiou, 2013b; but cf. Kuperman, van Dyke, \& Henry, 2016).

By developing and elaborating this rationale, de Jong (2011; see also Rodríguez, van den Boer, Jiménez, \& de Jong, 2015; van de Boer \& de Jong, 2015) hypothesized that the relationship between RAN and discrete word reading could reveal the extent to which word reading processes rely on serial operations. Specifically, if children rely on a serial decoding strategy, word reading should correlate more strongly with serial naming than with discrete naming, irrespective of the format of the reading task. In contrast, if children read words by sight, then naming and reading of the same format (i.e., both serial or both discrete) should correlate more strongly than tasks of different format, because (a) discrete naming and discrete reading would both reflect single-step intake of the individual stimuli, whereas (b) serial naming and serial reading would both reflect sequential processing of successive stimuli (in addition to lexical access and other common visual, phonological, and articulatory processes involved in the processing of individual stimuli in both tasks). Indeed, de Jong (2011) found that the link between naming and reading was format specific among experienced readers, while serial RAN remained a stronger correlate of both single-word and word-list reading than discrete naming among novice readers. These findings were subsequently replicated by Protopapas et al. (2013a) in a sample of Greek children in Grades 2 and 6, confirming that RAN can be a useful indicator 
of intra-word multi-element processing. According to this notion, individual words are perceptually treated as composed of multiple elements, which are not processed simultaneously, and this is revealed by the correlation of discrete word reading with RAN.

Moving beyond these findings, Protopapas et al. (2013a) also pointed out that discrete word reading was a strong predictor of serial word reading among beginning readers, indicating that words were processed in a similar manner whether presented individually or in lists. In contrast, RAN was a better predictor of serial word reading among advanced readers, suggesting that word sequences were processed like arrays of overlearned symbols. A strong serial advantage was also observed in both naming and reading, attributed to temporally overlapping (i.e., simultaneous) processing of successive elements (words or digits) in the serial tasks by the skilled readers.

Based on these findings, Protopapas et al. (2013a) suggested that skilled performance is based on cascaded processing, in which multiple items (words or digits) are processed in parallel. Specifically, individual items are processed sequentially through a series of processing stages, but successive items can simultaneously undergo processing in different stages, as if passing through a fixed-size buffer. For example, one item may be mapped onto its phonological representation while the previous one is articulated and the next one viewed. Consistent with this idea of internal buffering, recent studies of eye movements have demonstrated a tight control of the gaze during reading (Laubrock \& Kliegl, 2015) and naming (Gordon \& Hoedemaker, 2016), in that participants regulate look-ahead to maintain a fixed distance between the currently viewed and the currently named item. This complementary approach to RAN considers it an indicator of inter-word multi-item processing. Again, a correlation with RAN is thought to expose multi- 
element processing, but in this case the individual elements are the words in a list, rather than constituent parts within the words.

In a reanalysis of discrete and serial reading performance, Zoccolotti, De Luca, and Spinelli (2015) suggested that self-pacing skill seems to be an important cognitive component of fluent reading beyond facility with particular individual words. In other words, in serial word reading (i.e., word fluency tasks), the balance between inter-word and intra-word processing will depend not only on the efficiency of processing the specific individual words (whether in a sequence of chunks or entirely by sight), but also on the general efficiency of cascaded processing by each individual person. Because RAN indexes both intra- and inter-word processing of multiple elements, the contribution of each component cannot be discerned in simple bivariate correlations of reading with RAN. Rather, multiple regressions must be used to differentially expose the two components by examining inter-word processing while simultaneously controlling for intra-word processing. In the present work we employ a set of matched discrete and serial naming and reading tasks because of their hierarchical relations, thanks to which significant effects in multiple regression analyses indicate unique contributions, interpretable as corresponding to additional processes or skills. In particular, we control for intraword processing using discrete word reading performance in regression models. In this way any significant contributions of serial naming to serial reading can be interpreted as indicative of inter-word processing, because intra-word processing is already accounted for.

\section{Comparisons Between Languages and Orthographies}

To date, studies on the connection between serial/discrete naming and reading have only been conducted in alphabetic orthographies. In the only cross-linguistic study conducted so far, van den Boer et al. (2016) tested the intra-word processing hypothesis across languages varying 
in orthographic consistency (Dutch being relatively consistent and English being opaque), assessing the effects of length (monosyllabic vs. multisyllabic) and lexicality (real words vs. pseudowords) on reading of children in Grade 5, that is, with relatively advanced reading skills. They found that words were processed similarly in the two orthographies at this age. Discrete reading of monosyllabic words correlated more strongly with discrete naming than with serial naming, indicating that at this age short words were read by sight (in parallel), irrespective of orthography. The main difference between the two languages was observed in the discrete reading of multisyllabic pseudowords, which correlated with both serial and discrete naming in English but only with serial naming in Dutch. This was interpreted as indicative of a reliance on reading strategies differentially involving larger and smaller orthographic units, respectively, because in inconsistent orthographies (i.e., English), units larger than single graphemes are more consistent (see Ziegler \& Goswami, 2005). Specifically, van den Boer et al. (2016) suggested that "children are encouraged to process in parallel units larger than a letter to accurately identify nonwords" in English, whereas "serial decoding of letters into sounds is a successful reading strategy for nonwords" in Dutch (p. 162). In this interpretation, the aforementioned rationale treating RAN as indexing intra-word multi-element processing was conditioned on crosslinguistic differences in grain size, suggesting that grain size influences the relationship between serial and discrete naming and reading, and therefore RAN can be used to shed light on word processing across languages.

Differences in the degree of correspondence between orthographic and phonological mappings have long been associated with reading performance (e.g., Aro \& Wimmer, 2003; Ellis et al., 2004; Seymour, Aro, \& Erskine, 2003; Wimmer \& Goswami, 1994). Children learning to read in orthographically consistent languages (e.g., Finnish, Greek, German) outperform children 
learning to read in orthographically inconsistent languages (e.g., English, French) in word and pseudoword recognition (e.g., Aro \& Wimmer, 2003; Ellis et al., 2004; Seymour et al., 2003). However, most cross-linguistic comparisons have focused on word (or pseudoword) reading accuracy. Accordingly, the popular psycholinguistic grain size theory (Ziegler \& Goswami, 2005) has focused mainly on accuracy as well (see comments in de Jong, 2006; Wimmer, 2006). It has not yet been established whether similar cross-linguistic differences would be found in word reading fluency. In fact, several researchers have argued that the cognitive processes underlying reading fluency do not depend on orthographic depth (e.g., Caravolas et al., 2012; Patel, Snowling, \& de Jong, 2004; Vaessen et al., 2010; Ziegler et al., 2010; however, see also Georgiou, Parrila, \& Papadopoulos, 2008). If this is true, it means that on the one hand we have discrete word processes, critically affected by differences in orthographic depth (and, by extension, in grain size); and on the other hand we have reading fluency processes, which are not similarly affected. In other words, cross-linguistic differences in individual word recognition that are attributed to orthographic transparency do not result in corresponding differences in the development of reading fluency. This suggests that word reading fluency does not depend critically on the efficiency of individual word recognition, at least past the beginner stage, because if it did then reading fluency would be subject to the same orthographic depth influences as single word reading accuracy. Instead, it must depend on partially distinct sets of cognitive skills (cf. Lipka, 2017; Zoccolotti et al., 2015).

Moreover, differences in the nature and degree of correspondence between orthographic and phonological units across languages are not exhausted along a unidimensional continuum, as "the basic unit size for the mapping of graphic units to language units" (Perfetti et al., 2007, p. 131) may also be affected by several other dimensions of cross-linguistic variability, including 
visual arrangement (Share \& Daniels, 2016). Currently, evidence on the relationship between serial and discrete naming and reading is drawn from languages that have linear alphabetic writing systems (English, Dutch, Greek), in which words are represented in horizontal (linear) strings of graphemes at the phonemic grain size. However, in other writing systems, words are represented in nonlinear visual arrangements and/or at different linguistic grain sizes. For example, in the morphosyllabic Chinese script, the primary unit is the character, which corresponds to a monosyllabic morpheme (e.g., Hanley, 2005; Mair, 1996). Characters are written in a series of squared-shaped objects of the same horizontal extent and usually include two components, namely a phonetic radical that gives some clues to the character's pronunciation (consistent in $23-26 \%$ of the compound characters when tone is taken into account; see Chung \& Leung, 2008) and a semantic radical that provides information about the meaning of the character. However, despite being composed by perceptually salient radicals, Chinese characters cannot be decoded compositionally, because it is not the case that each radical determines the pronunciation of a part of the corresponding word in the way adjacent graphemes map onto adjacent phonemes in alphabetic writing systems. Rather, the entire character must be mapped onto the corresponding semantic and phonological representations. Therefore, no intra-word multi-element processing is possible for Chinese. This implies that Chinese discrete word reading should not correlate with RAN beyond discrete naming effects.

Standing apart from both alphabetic and morphosyllabic writing systems, Korean Hangul is a writing system with unique features (King, 1995), combining properties of alphabets and syllabaries, thus sometimes termed "alphasyllabary" (Kim, 2011) or "alphabetic syllabary" (Pae, 2011; Taylor \& Taylor, 1995). Specifically, in Hangul, individual letters correspond transparently to phonemes, as in other alphabets, but unlike European alphabetic writing they are 
not arranged sequentially along a line, like beads on a string. Rather, they are visually organized in syllable-sized blocks of a nonlinear structure (i.e., left-to-right and top-to-bottom within the syllable square; Cho \& McBride-Chang, 2005) ${ }^{1}$. The syllable blocks are roughly square-shaped and in this sense superficially resemble Chinese characters; however, unlike Chinese characters they are decomposable into a sequence of phonemically transparent elements. Thus, even though mapping to linguistic units is transparently discernible (and easily learnable) at the letterphoneme level, the syllable constitutes the visually prominent basic unit of the writing system (Cho \& Chiu, 2015; Kim, 2011; Pae, 2011) with which skilled readers are familiar. In light of this, it is not surprising that syllable awareness is related to word reading and spelling among Korean preschool children after accounting for print-related skills and phoneme awareness (Kim, 2011). However, it is not entirely clear how Korean words are processed, from the intra-word perspective expounded above: Although multi-element intra-word processing is possible, due to the transparent grapho-phonemic mapping of individual letters, whole-syllable parallel strategies are also plausible, given instructional history and readers' familiarity with the whole syllables.

\section{Cross-Linguistic Implications for Discrete and Serial Naming}

Although Chinese and English are considered inconsistent orthographies and Korean and Greek are considered relatively consistent orthographies, these pairs of orthographic systems differ in the salient units of grapheme-phoneme correspondence and in the way the units are internally structured and visually arranged. If the availability, or efficiency, of different reading strategies is affected by these differences, then we would expect systematic cross-linguistic differences in the relationship of serial and discrete word reading and digit naming, reflecting differential reliance on unit size and associated strategies.

\footnotetext{
${ }^{1}$ See https://en.wikipedia.org/wiki/Hangul\#Morpho-syllabic_blocks for illustrations
} 
Specifically, with respect to intra-word processing, orthographic depth considerations lead to the prediction of reliance on larger grain sizes among readers of less transparent orthographies (English and Chinese), associated with more efficient parallel (i.e., sight-word) reading of familiar short words that should be revealed by relatively stronger contributions from discrete digit naming to discrete word reading. In comparison, reliance on smaller grain sizes should be discernible for developing readers in the more transparent orthographies (Korean and Greek), evident in stronger contributions from serial digit naming to discrete word reading.

Extending this rationale to inter-word processing, effective large-unit reading in the less transparent orthographies should permit faster word recognition, in turn allowing more efficient scheduling of the serial operations underlying reading fluency, resulting in relatively stronger contributions from serial digit naming to serial word reading. In comparison, if small-unit strategies predominate in the more transparent orthographies, then word fluency might still be strongly related to discrete word reading, as inter-word operations will be disrupted by the additional effort at the single word level. Thus, relatively less strong contributions from serial digit naming to serial word reading should be observed.

If, however, aspects of orthographic systems other than the unidimensional consistency in the mapping between orthographic and phonological units are relevant for the development of reading fluency and, therefore, for its relation to discrete and serial naming, then different patterns of shared variance might emerge. Specifically, if nonlinear visual arrangement facilitates processing of monosyllabic words, through direct mapping at the syllabic level, then we should observe stronger evidence for sight word reading in Korean, as in Chinese; that is, discrete word reading would be more strongly related to discrete digit naming. From an inter-word perspective, if syllable-level processing is induced by the orthographic system regardless of internal 
consistency at the lower level of phonemes then we should observe more efficient processing of serial word arrays in Chinese and Korean. That is, in these languages, serial word processing would be less strongly related to discrete word processing and more strongly related to serial digit naming.

\section{The Present Study}

The present study examines the relationship between serial and discrete naming and reading across four languages representing three writing systems (logographic, alphasyllabic, and alphabetic) and widely distant points on the orthographic consistency continuum (for English and Greek). Our goal was to examine the extent to which intra-word and inter-word processes can be indexed by digit naming tasks across languages, by regressing discrete and serial word reading onto discrete and serial digit naming following a conceptual hierarchy of incrementally more inclusive tasks. To permit valid comparisons between languages and tasks, careful matching of items was undertaken, so that different tasks could be assumed to differ only in the underlying processes and not in superficial features of the materials. Specifically, within each language, items (i.e., number words and printed words) were matched in frequency and in phonological and orthographic structure to keep naming requirements constant across tasks. Thus, any observed differences cannot be attributed to phonological, orthographic, or articulatory demands. This necessarily limited our selection of words to those that could be matched to the digits in each language, regardless of the typicality of the number words or other cross-linguistic considerations.

We focused on the relationship between word reading and digit naming in a sample of intermediate readers for whom the development of sight-word reading is underway, but not yet fully developed. We explored both intra-word and inter-word processing based on the 
aforementioned relations between word reading and digit naming. Specifically, we examined the relationship of discrete word reading with (a) serial digit naming (i.e., RAN), indicating reliance on non-simultaneous intra-word processing of multiple elements and (b) discrete digit naming, indicating holistic processing of items (i.e., reading by sight). As a task, serial digit naming subsumes discrete digit naming in the sense that it also includes naming of individual digits in addition to their sequential processing. Therefore, any significant contribution of serial digit naming to discrete word reading would reveal differential involvement of "serial" word reading strategies across languages, beyond single symbol naming.

We also examined the relationship of word reading fluency (i.e., serial word reading) with (a) discrete word reading, accounting for word identification variance and possible intraitem processing; (b) serial digit naming, accounting for variance in multiple item processing; and (c) discrete digit naming, accounting for visual and articulatory processing of individually presented items processed holistically. Importantly, serial word reading subsumes discrete word reading, in the sense that individual words must be recognized and read in both tasks, but sequential processing of words is only required in the former. Because serial processing within individual words is already accounted for in the discrete words measure, this crucial asymmetry permits us to identify the importance of sequential processing to reading fluency, beyond discrete word reading. This can be achieved by examining the contribution of serial digit naming to serial word reading, over and above discrete digit naming and word reading, across languages.

Based on the finding of Protopapas et al. (2013a) that Grade 2 Greek children read word sequences much like individual words, and on the conclusion of van den Boer et al. (2016) that by Grade 5 Dutch and English children read familiar monosyllabic words by sight, the present study recruited children from Grade 3, aiming to discern associations at early stages of reading 
fluency development. However, due to extreme and uncontrolled differences not only in orthography but also in school practices and reading instruction, which make it impossible to control reading skill or functional reading experience across such widely differing orthographies and cultures without confounding other crucial developmental factors, we make no claim as to the comparability of the samples across languages beyond the similar ages and years of formal reading education.

\section{Learning to Read Chinese, Korean, English, and Greek}

The reading practices in China, Korea, Canada, and Greece vary as a function of the orthographic characteristics of each language. In China, teachers use pinyin (a phonetic representation of Chinese) to teach new characters during the early elementary school years. In Korea, Korean Hangul is taught starting with CV (consonant + vowel) syllables and moving to individual alphabet letters later. In Alberta, where the English-speaking Canadian children were recruited, most teachers use a synthetic phonics approach to teach reading, which emphasizes letter-sound correspondences and sound blending. Finally, in Greece, reading instruction is almost uniformly based on analytic and synthetic phonics. Children are instructed in phoneme blending as soon as they learn the very first letter sounds, progressing rapidly to syllables, short words, and sentences (for more information see the corresponding chapters in Verhoeven \& Perfetti, 2017). Formal literacy instruction begins in Grade 1 in all four countries, as the kindergarten curriculum focuses on language development, including, for example, vocabulary, shared reading of illustrated books, and phonological activities (Greece and Alberta), but no reading instruction (except for teaching of letters in Alberta; however, private/home teaching of Hangul is common in Korea during kindergarten years). 


\section{Method}

\section{Participants}

The participants were 113 Mandarin-speaking Chinese (48 girls; mean age $=109.58$ months, $S D=3.59$ ), 100 Korean (50 girls; mean age $=108.70$ months, $S D=4.03), 112$ Englishspeaking Canadian (57 girls; mean age $=105.62$ months, $S D=4.12$ ), and 108 Greek (54 girls; mean age $=107.54$ months, $S D=3.78)$ children attending Grade 3 in inner-city, public schools in Shanghai, Changwon, Edmonton, and Athens, respectively. All children were recruited on a voluntary basis from the general student population, were native speakers of their language, and none was experiencing any intellectual, sensory, or behavioral difficulties. Based on the location of the schools, as well as on parental education and income information reported in previous studies with children in these schools (see Deng, Silinskas, Wei, \& Georgiou, 2015; Manolitsis, Georgiou, \& Landerl, 2016), we can say that our participants came from families of middle socio-economic background. The Greek- and English-speaking children had approximately four years of formal education (including the kindergarten year). Korean children had three years of formal education; note, however, that most Korean children attend kindergarten for one or two years, even though it is not compulsory, prior to the onset of formal education at Grade 1 . The Chinese-speaking children had six years of formal education (three in kindergarten and three in elementary school). All children were in their third year of formal literacy instruction. Parental consent was obtained prior to testing.

\section{Materials}

Naming. Each task included nine repetitions of four digits (Arabic numerals). These were 2, 3, 5, and 6 in English, Chinese, and Greek. However, the words for numbers 2 and 5 correspond to single-vowel words in Korean (/i/ and /o/, respectively). Therefore, the digits 1 and 
4 were used instead, to control the naming demands among items and tasks within the Korean language. (See Appendix A for stimulus lists and properties).

Reading. Two sets of 36 high-frequency monosyllabic words were used in English, Korean, and Chinese. However, only a few monosyllabic words exist in Greek (Protopapas \& Vlahou 2009), not including any of the numbers 1-6. Therefore, all words used in the Greek reading tasks were bisyllabic, to match the number words used in the naming tasks. Within each language, the words were matched in frequency, number of graphemes and phonemes, and syllabic structure to each other and to the four number words (see Appendices A and B).

\section{Procedure}

Serial tasks. All 36 items were presented simultaneously in grid formats of four rows of nine on a 15.4" computer screen, in a quasi-random order precluding item repetitions (fixed across participants). Children were instructed to name out loud all digits or read all words as quickly as possible. Instructions and practice items were provided prior to each trial to ensure compliance with task demands.

Discrete tasks. Digits or words were presented individually, centered on the computer screen, in a fixed quasi random order precluding immediate repetitions. Children were instructed to name out loud each digit (or read each word) presented on the screen as quickly as possible. Each task was preceded by four practice items with feedback.

For both serial and discrete tasks, item presentation and response recording was controlled by the DMDX experimental display software (Forster \& Forster, 2003). Items were presented in black 20-pt Consolas font on a white background and remained on the screen until the experimenter pressed a key to proceed to the next item, as soon as complete production of a response was registered. Individual responses were recorded in audio files through a head- 
mounted microphone and the total naming or reading time was determined off-line using CheckVocal (Protopapas, 2007).

For discrete tasks, naming or reading times of individual items were recorded; for serial tasks, total naming or reading times of the entire array were recorded. All recorded response times (RTs) analyzed below included both onset latency and articulation time. RTs were transformed to a common scale of "items per second" by inversion. For discrete tasks, a single score for each participant was computed by averaging RTs across correctly named (or read) items. Errors in serial tasks were ignored.

Testing took place in April/May/June (8-10 months into the academic year) in Greece, China, and Canada, and in June/July (4-5 months into the academic year) in Korea. The naming and reading tasks were administered in random order during a 40-minute session including additional tasks not reported here. Each child was tested individually by a trained assistant. A well-defined protocol and training procedure ensured uniformity of testing across sites.

\section{Results}

\section{Preliminary data analysis}

Table 1 shows the descriptive statistics for each measure excluding data points associated with outliers (one in Chinese, one in Korean, three in English, and five in Greek; defined as discrete naming accuracy $<67 \%$, a criterion based on examination of Q-Q plots; see Figure S1 in online supplementary materials), or with technical problems (five children in English). The exclusionary criteria left 112 complete datasets in Chinese, 99 in Korean, 105 in English, and 103 in Greek. Discrete naming accuracy for these children is shown in Table 2. Examination of Q-Q plots (Figure S2) and Shapiro-Wilk tests (Table S1) indicated no major deviations from normality for the target measures (items per second). All analyses were conducted using R ( R 
Core Team, 2015) with the cleaned-up dataset.

Table 3 displays the correlation coefficients among tasks, separately for each language.

Overall, the patterns of correlations appear quite similar. In particular, the magnitude of the correlations across languages appears to depend on task format, with higher correlations observed among digits and words of the same format (serial or discrete) than of different format.

\section{Serial and Discrete Naming as Predictors of Discrete Word Reading}

To probe the nature of intra-word processing (measured by discrete words) across languages, path analysis was conducted using R package openMX 2.0 (Neale et al., 2016). A saturated baseline model (Figure 1, top) was first fitted to the data for each language, with discrete word reading as the outcome variable and serial and discrete digits as the predictor variables. Both predictors were significant in Greek. Discrete digits was the only significant predictor in English, Korean, and Chinese (see Table 4).

We then performed multigroup analyses, starting with an unconstrained model including all paths and proceeding with the implementation of equality constraints between languages, first on the regression coefficients, then on the means and intercepts, and finally on the covariance and residual variances. In each group of parameters, constraints were iteratively applied to the most similar parameter estimates, and were retained only if they did not cause a significant deterioration of the model's fit, determined by BIC and $\chi^{2}$ test.

Figure 1 (bottom) displays the 18-parameter multigroup model resulting from this procedure, not significantly different from the 36-parameter saturated model $\left(\chi^{2}=26.9\right.$, df $=18$, $p=.080 ; \mathrm{CFI}=.981 ; \mathrm{TLI}=.988 ; \mathrm{RMSEA}=.034,95 \% \mathrm{CI}[0, .064]) .($ Table S2 lists the estimated parameters for the unconstrained model and Table S3 for the final constrained one.) The path from serial digits to discrete words was equal across three of the four languages. The 
paths from discrete digits to discrete words differed between deep and shallow orthographic systems, that is, it was equal between Greek and Korean and between English and Chinese, despite differences in orthographic unit size and visual arrangement. Absolute performance (i.e., task means) in digit naming (both formats) differed between languages, whereas the intercept of discrete words did not differ between English, Korean, and Chinese.

\section{Discrete Word Reading, Serial Naming and Discrete Naming as Predictors of Serial Word Reading}

To probe the nature of inter-word processing (measured by serial words) across languages, path analysis was conducted using the same procedure and tools as in the previous section. A saturated baseline model (Figure 2, top) was first fitted to the data for each language, with serial word fluency as the outcome variable and discrete words, serial digits, and discrete digits as the predictor variables. All three predictors were significant in Greek and English; discrete words and serial digits were significant in Korean; and only serial digits was significant in Chinese (see Table 4).

Figure 2 (bottom) displays the 29-parameter multigroup model resulting from applying equality constraints, not significantly different from the 56-parameter saturated model $\left(\chi^{2}=36.9\right.$, $\mathrm{df}=27, p=.098 ; \mathrm{CFI}=.987 ; \mathrm{TLI}=.988 ; \mathrm{RMSEA}=.030,95 \% \mathrm{CI}[0, .055]) .($ Table $\mathrm{S} 4$ lists the estimated parameters for the unconstrained model and Table S5 for the final constrained one.) Notably, the path from serial digits to serial words was equal across all four languages, as were the serial digits and serial words residuals, indicating a universal relationship between serial naming and reading fluency at this age. However, the paths from discrete words and discrete digits to serial words differed between linear and nonlinear systems, but were equal between systems differing in transparency (i.e., between Greek and English and between Korean and 
Chinese). A suppressive effect of discrete digits was observed among the linear alphabetic orthographies. Absolute performance (i.e., task means) in digit naming (both formats) differed between languages, whereas the mean of discrete words did not differ between Greek and English or between Korean and Chinese.

\section{Discussion}

We investigated the relationship between serial and discrete naming and reading across four languages with different writing systems in an attempt to better understand the role of single-item (intra-word) and multi-item (inter-word) processing in the attainment of word reading fluency. In the analysis with discrete word reading time as the outcome measure, our results showed that (a) serial digit naming was a significant predictor only in Greek (in which items were two syllables long); and (b) discrete digit naming was a significant predictor in all four orthographies, but the association was significantly stronger for the transparent ones (Greek and Korean). In the analysis with serial word reading time as the outcome measure, our results showed that (a) serial digit naming was the only predictor that was significant across all orthographies and, crucially, its contribution did not differ between orthographies; and (b) a distinction between linear and nonlinear writing systems was evident in the pattern of relationships with the discrete naming/reading measures. These results suggest a universal relationship between serial digit naming and word reading fluency, across languages and orthographic systems, in the context of variations in the interrelations among naming tasks that may be modulated by aspects of orthographies such as transparency and linearity. In the following, we discuss our findings in more detail, focusing first on the predictors of discrete word reading (intra-word) and then on those of serial word reading (inter-word). 


\section{Discrete Word Reading Time}

With discrete digit naming controlled for, serial digit naming time was not significantly associated with discrete word reading time in three of the four orthographies. The lack of a significant effect from serial digits to discrete words can be interpreted as an indication of sightword processing in three of the four languages, consistent with the prediction of de Jong (2011) and the findings of van den Boer et al. (2016). However, this interpretation cannot fully account for the Greek results. Specifically, in Greek, both serial digit naming and discrete digit naming were significant predictors of discrete word reading, suggesting "serial" and "parallel" processing, respectively. If we conceive of the relationships with the serial vs. discrete naming as indicative of two mutually incompatible processes, this pattern of results is unintelligible.

At the same time, discrete digit naming was more strongly associated with discrete word reading in Greek and Korean than in English and Chinese. Although there are many similarities and differences among the four orthographies, one obvious similarity between Greek and Korean, contrasting them with English and Chinese, is their relative transparency. Based on that, we may speculate that this finding indicates more efficient intra-word processing, consistent with the general understanding that reading develops faster in more transparent orthographies (e.g., Ellis et al., 2004; Seymour et al., 2003). It stands to reason that an efficient network of distributed graphophonemic connections will develop stronger and faster when the connections are consistent across items (Plaut, McClelland, Seidenberg, \& Patterson, 1996). This is not to say that transparent orthographies favor larger processing units but, rather, that small processing units are consistently mapped and thereby also enable the development of efficient larger units as well, simultaneously permitting connections over multiple sizes (Ehri, 2005, 2014). According to the psycholinguistic grain size theory (Ziegler \& Goswami, 2005), less transparent orthographies 
are forced to rely on larger processing units only because smaller units are unreliable. This entails a relative within-orthography advantage, whereby larger units are processed more reliably and more efficiently than smaller units. It also entails a between-orthography advantage in the processing of smaller units, which is efficient in transparent orthographies, but ineffective in opaque ones. However, there is no logical entailment of between-orthography differences in the efficiency of processing larger units: The fact that reading English must rely on chunks of letters — whereas reading Greek or Korean can be based on both small and large groups — does not imply that reading multi-letter groups in English is more efficient than reading multi-letter groups in Greek or Korean.

To account for the finding that both serial and discrete naming are related to word reading, van den Boer et al. (2016) entertained the notion that some items could be processed serially whereas others are processed by sight (a between-items difference); or that parts of items (e.g., letter clusters or syllables) could be processed serially whereas others are processed in parallel (a within-items difference). Both of these options retain a strict dichotomy between mutually incompatible underlying serial and parallel processes, indexed by serial and discrete naming, respectively, consistent with a strict dichotomy between "decoding" vs. "sight-word" reading strategies. Acknowledging that a strict dichotomy may primarily constitute a theoretical convenience rather than empirical solid ground, we can nevertheless capitalize on this distinction to incorporate the Greek findings into the interpretation. Recall that the requirement of equating item properties between tasks within each language forced us to use two-syllable items in Greek, because most Greek number words have two syllables. (In contrast, single-syllable items were used in the other languages, to match the monosyllabic number words.) The two syllables call for within-word multi-element processing, indexed by serial digit naming and accounting for the 
respective correlation. At the same time, number words are quite common in Greek, as in the other languages, and presumably comparably familiar to children; thus, they should be considered well-known, frequent words across languages. The same must hold for the word lists that were specifically matched to the number words in each language, as well as to their individual syllables. A "parallel" aspect of word processing is then naturally ascribed to the rapid identification of these words (in the three languages), or their constituent syllables (in Greek).

In this (admittedly speculative) framework, word length accounts for the discrepancy between Greek and the other languages and highlights two issues relevant for future studies: First, item properties need to be more rigidly controlled across languages; and second, an absolute theoretical distinction between mutually exclusive "parallel" and "serial" processing may be too rigid, especially if taken to imply associated efficiency distinctions such as fast vs. slow processing, respectively. In support of a cross-linguistic interpretation of our findings, attributing the discrepancy to the superficial length factor, we also note that Greek is known from previous studies to produce specific patterns of correlations between naming and reading that align very well with those reported in Dutch, Italian, and English (e.g., Georgiou, Parrila, Cui, \& Papadopoulos, 2013; Protopapas et al., 2013a); therefore, there is no indication that Greek might be some sort of an outlier or aberrant orthography.

In sum, the intra-word investigation produced results consistent with (a) more efficient sight-word reading in the two consistent orthographies (Greek and Korean) than in the inconsistent ones (English and Chinese); and (b) some reliance on multi-element intra-word processing for the longer Greek words, not evident in the other orthographies. If these differences transferred transparently to inter-word processing differences, we should have found 
a similar distinction on the basis of consistency plus a Greek exception. However, this is not at all what the results showed.

\section{Serial Word Reading Time}

Turning to the examination of the predictors of serial word reading time (i.e., word reading fluency), the most striking finding was the uniformity, across languages, in the relationship between serial digit naming and serial word reading, when discrete naming and reading were controlled. This result is consistent with a universal substrate of word reading fluency across writing systems that is independent of the vagaries of individual word recognition. Universality of cognitive processes underlying text processing has also been claimed on the basis of eye movement patterns during reading in different orthographies (Finnish, English, Chinese; Liversedge et al., 2016). Even when differences between orthographies are associated with different eye movement patterns in beginner and intermediate readers, skilled reading converges toward similar processing across orthographies as the reading process becomes increasingly lexicalized (Rau et al., 2016).

In our data, despite the different patterns of associations between serial word reading and the discrete naming and reading measures, the specific association between serial digit naming and serial word reading was constant across languages (consistent with Georgiou et al., 2016). This unique significant contribution from serial digits to serial words-beyond the direct effect of discrete words - demonstrates that individual differences in serial word reading (i.e., word reading fluency) are not fully determined by variance in single word recognition. Instead, we suggest that reading fluency expresses a distinct underlying cognitive skill related to efficient endogenous scheduling of sequences, which has previously been termed cascaded processing (Protopapas et al., 2013a; see also Zoccolotti et al., 2015). Evidently, the contribution of this skill 
to word reading fluency, over and above individual differences in discrete word reading, is universal, as it was found to be statistically indistinguishable across widely different orthographies.

It is also notable that discrete word reading was a significant predictor of serial word reading in Greek and English, while discrete naming contributed negatively in both of these languages, indicating suppression (Friedman \& Wall, 2005; Maassen \& Bakker, 2001). The suppressive effect of discrete digit naming on word reading fluency is consistent with previous reports in both English (Logan \& Schatschneider, 2014; Logan, Schatschneider, \& Wagner, 2011) and Greek (Protopapas et al., 2013a), indicating that processes underlying individual item naming are not the crucial element of the RAN-reading relationship. No suppressive effect was detected in Korean or Chinese, in which discrete naming was not even a significant predictor of word reading fluency. Similar findings in Japanese, another nonlinear writing system, have shown that only serial naming contributes to serial word reading, while the role of discrete naming is not significant (Wakamiya et al., 2011).

Notably, in our data, it is discrete word reading variance that was mainly suppressed by discrete digit naming, and not serial digit naming variance. That is, in hierarchical regression analysis of serial word reading — excluding and including discrete digit naming — the coefficient of discrete word naming increased with the inclusion of discrete digit naming, indicating that isolated naming acts as a suppressor for a portion of the variance in discrete word reading that is not necessary for word reading's relation with reading fluency. In other words, the contribution of discrete word reading to serial word reading was not primarily related to aspects of individual symbol naming but, rather, to other processes specifically involved in word identification. This is important because the contribution from discrete word reading to word fluency is typically 
thought to be primarily modulated by the "automaticity" of individual word processing, which, in the case of highly efficient sight-word reading, might be thought to be similar to naming of overlearned symbols, such as digits. If, however, the contribution from discrete words to reading fluency is not due to variance shared with discrete digit naming, this conceptualization of wordbased reading fluency may need to be reconsidered and perhaps related to other processes. We speculate that these other processes are related to the relative difficulty in word recognition resulting from orthographic inconsistency in English and from the additional word length in Greek. In contrast, efficient recognition of the single-syllable words used in this study by Korean and Chinese children permitted unimpeded application of cascaded processing to the words in serial word reading, obviating effects of discrete word reading or discrete digit naming.

\section{Limitations and Conclusions}

In sum, the theoretical distinction between orthographies that differ in transparency alone cannot explain the dissimilar findings between different languages observed in our study. The assumption of a facilitative effect of a consistent writing system on the development of accurate and fast word reading, allowing reading fluency to emerge earlier, was not uniformly observed in our study, but was moderated by other factors. Children who learn to read Greek, a consistent orthography, demonstrated similar patterns of performance to children who learn to read English, an inconsistent orthography; we ascribed these similarities to differences in word length affecting the relative efficiency (or applicability) of different strategies available at this age for the items used in the study. In a similar vein, unexpected similarities were observed between children who learn to read Korean and Chinese that may be due to instructional practices and visual properties of the orthography. These findings cannot be attributed to orthographic depth or grain size alone, but show that additional factors must be taken into account to understand these cross-linguistic 
patterns.

Specifically, whole-word processing may seem justified for Chinese due to the opacity of the system presumably forcing children to process characters holistically. It is less expected for Korean, in which individual letters map transparently to phonemes, as in linear alphabetic systems. This pattern may be ascribed to holistic processing for both Chinese and Korean, based on their visually-similar syllabic arrangement. That is, when items consist of more highly integrated symbols (i.e., single characters or letter groups arranged in blocks), irrespective of the degree of visual complexity or whether information is more or less densely packed (Chinese vs. Korean), readers tend to process these items as single chunks. This interpretation is in line with the fact that Korean children are first taught a basic CV syllabary and are only subsequently introduced to individual grapheme-phoneme mappings. Even though the transparency of the mappings at the grapheme-phoneme level supports efficient learning of smaller units, a processing bias may already be established by early instructional practices, to be continuously reinforced in the acquisition of reading experience on the basis of the visual arrangement.

Some limitations of the present study are worth mentioning. First, we only assessed Grade 3 children. It is possible that orthographic consistency exerts an effect on reading processes in alphabetic languages, but only at the initial phases of reading development (e.g., Goswami et al., 1997; Seymour et al., 2003). Thus, by assessing Grade 3 children we may have missed the opportunity to detect these differences. Second, we administered only monosyllabic words in three orthographies and we do not know if similar results would have been observed with multisyllabic items or pseudowords. In contrast, we administered bisyllabic words in Greek, confounding an item-length difference with a language difference. This confound was necessitated by the reality of number words in each language but it limits the interpretability of 
our findings and has led to a number of speculative suggestions. On the other hand, the possibility that patterns of correlations among reading and naming tasks may be crucially affected by superficial aspects of the stimuli has largely been overlooked in naming research. Our findings (and speculative interpretations) suggest that this should be rectified in future studies, by imposing tighter control over stimulus properties, including cross-linguistic matching, to support solid conclusions. Third, because our Chinese sample was recruited in Shanghai city it is possible that our participants spoke not only Mandarin, but also Shanghainese. Although we did not directly test our participants' knowledge of Shanghainese, data we collected for a previous study examining the role of home literacy environment in Chinese reading indicated that $95 \%$ of the parents from these same schools reported Mandarin as the language spoken at home (Deng et al., 2015). Thus, we have no reason to believe that our current sample-recruited from the same schools a year apart—is any different. Finally, we assessed only Mandarinspeaking Chinese children who learn to read a simplified script. Thus, our results may not generalize to Cantonese-speaking Chinese children who learn to read a traditional script.

In conclusion, our findings have some important theoretical implications: First, they show that irrespective of orthographic consistency and writing system, serial naming is highly (and equally) predictive of word fluency, once discrete word reading is controlled. Therefore, even in languages where a decoding strategy is not available or not reliable, the substantial unique contribution of serial naming corroborates the hypothesis that RAN reflects inter-word processing, that is, efficient scheduling of processing multiple stimuli simultaneously through different stages (i.e., cascaded processing; Protopapas et al., 2013a). Second, our findings show that Grade 3 Chinese and Korean readers are more proficient than English-speaking readers with materials of comparable familiarity and complexity, possibly indicating that Chinese and Korean 
readers have more advanced sight-word reading skills and can rely more on serial inter-item processing than English readers. Greek readers are also more proficient than English readers, because they achieved the same level of performance and the same pattern of interrelations but with more complex materials (bisyllabic instead of monosyllabic items), consistent with more advanced reading skills due to the greater transparency of Greek. These results are especially noteworthy in that they limit the potential of the prevalent orthographic depth hypothesis to account for cross-linguistic differences in reading and invite a more nuanced perspective on writing system-specific variation. Thus, we argue that differences between writing systems or orthographies within the same writing system are subject to the constraints imposed by aspects of written language. Therefore, rather than being language-specific, these differences emerge through the functionality of orthographic units and the nature of the writing system, as well as its interaction with the level of reading proficiency. 


\section{Acknowledgements}

Data collection in Alberta was supported in part by an Alberta Advisory Committee for Educational Research grant (RES0023352) to GKG; data collection in Korea was supported in part by the National Research Foundation of Korea Grant funded by the Korean Government (NRF-2016S1A2A2912359) to JRC. 


\section{References}

Altani, A., Protopapas, A., \& Georgiou, G. K. (2017). The contribution of executive functions to naming digits, objects, and words. Reading and Writing, 30, 121-141.

Aro, M., \& Wimmer, H. (2003). Learning to read: English in comparison to six more regular orthographies. Applied Psycholinguistics, 24, 621-635.

Caravolas, M., Lervåg, A., Mousikou, P., Efrim, C., Litavský, M., Onochie-Quintanilla, E., ... \& Hulme, C. (2012). Common patterns of prediction of literacy development in different alphabetic orthographies. Psychological Science, 23, 678-686.

Cho, J.-R., \& Chiu, M. M. (2015). Rapid naming in relation to reading and writing in Korean (Hangul), Chinese (Hanja) and English among Korean children: a 1-year longitudinal study. Journal of Research in Reading, 4, 387-404.

Cho, J.-R., \& McBride-Chang, C. (2005). Correlates of Korean Hangul acquisition among kindergartners and second graders. Scientific Studies of Reading, 9, 3-16.

Chung, F. H.-K., \& Leung, M.-T. (2008). Data analysis of Chinese characters in primary school corpora of Hong Kong and mainland China: preliminary theoretical interpretations. Clinical Linguistics \& Phonetics, 22, 379-389.

Coltheart, M. (1981). The MRC Psycholinguistic Database. Quarterly Journal of Experimental Psychology, 33A, 497-505.

de Jong, P. F. (2006). Units and routes of reading in Dutch. Developmental Science, 9, 441-442.

de Jong, P. F. (2011). What discrete and serial rapid automatized naming can reveal about reading. Scientific Studies of Reading, 15, 314-337.

Denckla, M., \& Rudel, R. (1976). Naming of object drawings by dyslexic and other learning disabled children. Brain and Language, 3, 1-15. 
Deng, C.-P., Silinskas, G., Wei, W., \& Georgiou, G. K. (2015). Cross-lagged relationships between home learning environment and academic achievement in Chinese. Early Childhood Research Quarterly, 33, 12-20.

Ehri, L. C. (2005). Learning to read words: Theory, findings, and issues. Scientific Studies of Reading, 9, 167-188.

Ehri, L. C. (2014). Orthographic mapping in the acquisition of sight word reading, spelling memory, and vocabulary learning. Scientific Studies of Reading, 18, 5-21.

Ellis, N. C., Natsume, M., Stavropoulou, K., Hoxhallari, L., van Daal, V. H. P., Polyzoe, N., ... \& Petalas, M. (2004). The effects of orthographic depth on learning to read alphabetic, syllabic, and logographic scripts. Reading Research Quarterly, 39, 438-468.

Forster, K. I., \& Forster, J. C. (2003). DMDX: A windows display program with millisecond accuracy. Behavior Research Methods, Instruments, \& Computers, 35, 116-124.

Friedman, L., \& Wall, M. (2005). Graphical views of suppression and multicollinearity in multiple linear regression. The American Statistician, 59, 127-136.

Georgiou, G., Aro, M., Liao, C.-H., \& Parrila, R. (2016). Modeling the relationship between rapid automatized naming and literacy skills across languages varying in orthographic consistency. Journal of Experimental Child Psychology, 143, 48-64.

Georgiou, G., Parrila, R., Cui, Y., \& Papadopoulos, T. C. (2013). Why is rapid automatized naming related to reading? Journal of Experimental Child Psychology, 115, 218-225.

Georgiou, G., Parrila, R., \& Papadopoulos, T. C. (2008). Predictors of word decoding and reading fluency in English and Greek: A cross-linguistic comparison. Journal of Educational Psychology, 100, 566-580. 
Gordon, P. C., \& Hoedemaker, R. S. (2016). Effective scheduling of looking and talking during rapid automatized naming. Journal of Experimental Psychology: Human Perception and Performance, 42, 742-760.

Hanley, R. J. (2005). Learning to read in Chinese. In M. J. Snowling \& C. Hulme (Eds.), The science of reading: A handbook (pp. 316 -335). Oxford, UK: Blackwell Publishing.

Kim, Y.-S. (2011). Considering linguistic and orthographic features in early literacy acquisition: Evidence from Korean. Contemporary Educational Psychology, 36, 177-189.

King, R. (1995). Korean writing. In P. T. Daniels \& W. Bright (Eds.), The world's writing systems (pp. 218-227). Oxford University Press.

Kuperman, V., van Dyke, J. A., \& Henry, R. (2016). Eye-movement control in RAN and reading. Scientific Studies of Reading, 20, 173-188.

Laubrock, J., \& Kliegl, R. (2015). The eye-voice span during reading aloud. Frontiers in Psychology, 6, 1432.

Lipka, O. (2017). Reading fluency from grade 2-6: A longitudinal examination. Reading and Writing, 30, 1361-1375.

Liversedge, S. P., Drieghe, D., Li, X., Yan, G., Bai, X., \& Hyönä, J. (2016). Universality in eye movements and reading: A trilingual investigation. Cognition, 147, 1-20.

Logan, J. A., \& Schatschneider, C. (2014). Component processes in reading: Shared and unique variance in serial and isolated naming speed. Reading and Writing, 27, 905-922.

Logan, J. A., Schatschneider, C., \& Wagner, R. K. (2011). Rapid serial naming and reading ability: The role of lexical access. Reading and Writing, 24, 1-25.

Maassen, G. H., \& Bakker, A. B. (2001). Suppressor variables in path models: Definitions and interpretations. Sociological Methods \& Research, 30, 241-270. 
Mair, V. H. (1996). Modern Chinese writing. In P. T. Daniels \& W. Bright (Eds.), The world's writing systems (pp. 200-208). Oxford University Press.

Manolitsis, G., Georgiou, G., \& Landerl, K. (2016, July). Developmental relations between home literacy environment and word reading across languages. Paper presented at the 23nd annual conference of the Society for the Scientific Studies of Reading, Porto, Portugal.

Masterson, J., Stuart, M., Dixon, M., \& Lovejoy, S. (2010). Children's printed word database: Continuities and changes over time in children's early reading vocabulary. British Journal of Psychology, 101, 221-242.

Meng, X.-L., Rosenthal, R., \& Rubin, D. B. (1992). Comparing correlated correlation coefficients. Psychological Bulletin, 111, 172-175.

Moll, K., Fussenegger, B., Willburger, E., \& Landerl, K. (2009). RAN is not a measure of orthographic processing. Evidence from the asymmetric German orthography. Scientific Studies of Reading, 13, 1-25.

National Institute of the Korean Language (2005). The Korean Corpus: Contemporary Korean usage frequency database. Seoul: Korea.

Neale, M. C., Hunter, M. D., Pritikin, J. N., Zahery, M., Brick, T. R., Kirkpatrick, R. M., Estabrook, R., et al. (2016). OpenMX 2.0: Extended structural equation and statistical modeling. Psychometrica, 81, 535-549.

Taylor, J. N., \& Perfetti, C. A. (2016). Eye movements reveal readers' lexical quality and reading experience. Reading and Writing, 29, 1069-1103.

Pae, H. K. (2011). Is Korean a syllabic alphabet or an alphabetic syllabary? Writing Systems Research, 3, 103-115. 
Parrila, R., Kirby, J. R., \& McQuarrie, L. (2004). Articulation rate, naming speed, verbal shortterm memory, and phonological awareness: Longitudinal predictors of early reading development? Scientific Studies of Reading, 8, 3-26.

Patel, T., Snowling, M. J., \& de Jong, P. F. (2004). A cross-linguistic comparison of children learning to read in English and Dutch. Journal of Educational Psychology, 96, 785-797.

Perfetti, C. A., Liu, Y., Fiez, J., Nelson, J., Bolger, D. J., \& Tan, L.-H. (2007). Reading in two writing systems: Accommodation and assimilation of the brain's reading network. Bilingualism: Language and Cognition, 10, 131-146.

Plaut, D. C., McClelland, J. L., Seidenberg, M. S., \& Patterson, K. (1996). Understanding normal and impaired word reading: Computational principles in quasi-regular domains. Psychological Review, 103, 56-115.

Protopapas, A. (2007). Check Vocal: A program to facilitate checking the accuracy and response time of vocal responses from DMDX. Behavior Research Methods, 39, 859-862.

Protopapas, A., Altani, A., \& Georgiou, G. K. (2013a). Development of serial processing in reading and rapid naming. Journal of Experimental Child Psychology, 116, 914-929.

Protopapas, A., Altani, A., \& Georgiou, G. K. (2013b). RAN backward: A test of the visual scanning hypothesis. Scientific Studies of Reading, 17, 453-461.

Protopapas, A., \& Vlahou, E. L. (2009). A comparative quantitative analysis of Greek orthographic transparency. Behavior Research Methods, 41, 991-1008.

Protopapas, A., Tzakosta, M., Chalamandaris, A., \& Tsiakoulis, P. (2012). IPLR: An online resource for Greek word-level and sublexical information. Language Resources \& Evaluation, 46, 449-459. 
R Core Team (2015). R: A language and environment for statistical computing. R Foundation for statistical computing, Vienna, Austria. Retrieved from: http://www.R-project.org/.

Rau, A. K., Moll, K., Moeller, K., Huber, S., Snowling, M. J., \& Landerl, K. (2016). Same same, but different: Word and sentence reading in German and English. Scientific Studies of Reading, 20, 203-219.

Rodríguez, C., van den Boer, M., Jiménez, J. E., \& de Jong, P. F. (2015). Developmental changes in the relations between RAN, phonological awareness, and reading in Spanish children. Scientific Studies of Reading, 19, 273-288.

Seymour, P. H. K., Aro, M., \& Erskine, J. M. (2003). Foundation literacy acquisition in European orthographies. British Journal of Psychology, 94, 143-174.

Share, D. L., \& Daniels, P. T. (2016). Aksharas, alphasyllabaries, abugidas, alphabets and orthographic depth: Reflections on Rimzhim, Katz and Fowler (2014). Writing Systems Research, 8, 17-31.

Taylor, I., \& Taylor, M. (1995). Writing and literacy in Chinese, Korean, and Japanese. Amsterdam: Benjamins.

Vaessen, A., Bertrand, D., Tóth, D., Csépe, V., Faísca, L., Reis, A., \& Blomert, L. (2010). Cognitive development of fluent word reading does not qualitatively differ between transparent and opaque orthographies. Journal of Educational Psychology, 102, 827-842. van den Boer, M., \& de Jong, P. F. (2015). Parallel and serial reading processes in children’s word and nonword reading. Journal of Educational Psychology, 107, 141-151.

van den Boer, M., Georgiou, G. K., \& de Jong, P. F. (2016). Naming of short words is (almost) the same as naming of alphanumeric symbols: Evidence from two orthographies. Journal of Experimental Child Psychology, 144, 152-165. 
Van Heuven, W. J. B., Mandera, P., Keuleers, E., \& Brysbaert, M. (2014). Subtlex-UK: A new and improved word frequency database for British English. Quarterly Journal of Experimental Psychology, 67, 1176-1190.

Verhoeven, L. T. W., \& Perfetti, C. A. (Eds.) (2017). Learning to read across languages and writing systems. Cambridge University Press.

Wakamiya, E., Okumura, T., Nakanishi, M., Takeshita, T., Mizuta, M., Kurimoto, N., \& Tamai, H. (2011). Effects of sequential and discrete rapid naming on reading in Japanese children with reading difficulty. Brain and Development, 33, 487-493.

Wei, W., Georgiou, G. K., \& Deng, C. (2015). Examining the cross-lagged relationships between RAN and word reading in Chinese. Scientific Studies of Reading, 19, 446-455.

Wimmer, H. (2006). Don't neglect reading fluency! Developmental Science, 9, 447-448.

Wimmer, H., \& Goswami, U. (1994). The influence of orthographic consistency on reading development: word recognition in English and German children. Cognition, 51, 91-103.

Wolf, M., \& Bowers, P. G. (1999). The double-deficit hypothesis for the developmental dyslexias. Journal of Educational Psychology, 91, 415-438.

Xiao, H. (2012). CNCORPUS: Chinese character frequencies list. Retrieved March $17^{\text {th }}$, 2016, from: http://www.cncorpus.org/resources/CorpusCharacterlist.xls

Zeng, R.-F. (2000). Report of Chinese characters and words in primary textbooks of mainland China. Retrieved March $18^{\text {th }}, 2016$, from: http://ws.moe.edu.tw/001/Upload/files/SITE_CONTENT/M0001/MAINLAND/ch21.htm 
Ziegler, J. C., Bertrand, D., Tóth, D., Csépe, V., Reis, A., Faísca, L., ... \& Blomert, L. (2010). Orthographic depth and its impact on universal predictors of reading: A cross-language investigation. Psychological Science, 21, 551-559.

Ziegler, J. C., \& Goswami, U. (2005). Reading acquisition, developmental dyslexia, and skilled reading across languages: A psycholinguistic grain size theory. Psychological Bulletin, $131,3-29$.

Zoccolotti, P., De Luca, M., Lami, L., Pizzoli, C., Pontillo, M., \& Spinelli, D. (2013). Multiple stimulus presentation yields larger deficits in children with developmental dyslexia: A study with reading and RAN-type tasks. Child Neuropsychology, 19, 639-647.

Zoccolotti, P., De Luca, M., \& Spinelli, D. (2015). Discrete versus multiple word displays: A reanalysis of studies comparing dyslexic and typically developing children. Frontiers in Psychology, 6, 1530. 


\section{Appendix A}

\begin{tabular}{|c|c|c|c|c|}
\hline Materials & Greek & Korean & English & Chinese \\
\hline Digits & $2,3,5,6$ & $1,3,4,6$ & $2,3,5,6$ & $2,3,5,6$ \\
\hline $\begin{array}{l}\text { Number } \\
\text { words }\end{array}$ & $\delta v^{\prime} \circ, \tau \rho i ́ \alpha, \pi \varepsilon \varepsilon^{\prime} \nu \tau \varepsilon, \varepsilon^{\prime} \xi l$ & 일, 삼, 사, 육 & two, three, five, six & 二, 三, 五, 六 \\
\hline Word list 1 & 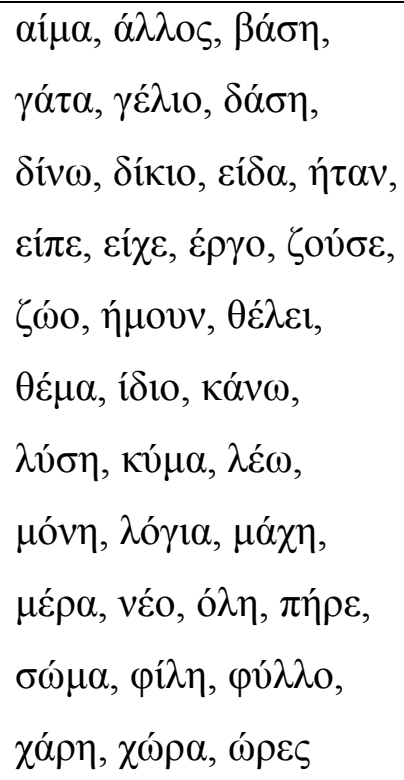 & $\begin{array}{l}\text { 앞, 잎, 인, 암, 읍, 엔, } \\
\text { 옥, 묘, 악, 문, 잠, 신, } \\
\text { 색, 섬, 정, 턱, 댐, 상, } \\
\text { 비, 키, 코, 게, 벼, 배, } \\
\text { 서, 노, 티, 솔, 연, 혹, } \\
\text { 북, 독, 슛, 용, 욕, 옆 }\end{array}$ & $\begin{array}{l}\text { air, boy, say, tea, } \\
\text { know, ask, bag, } \\
\text { bed, cat, cup, let, } \\
\text { pot, run, sit, son, } \\
\text { ball, been, boat, } \\
\text { book, cake, deep, } \\
\text { feel, food, girl, } \\
\text { slow, tall, horse, } \\
\text { light, noise, watch, } \\
\text { fox, white, cold, } \\
\text { hand, milk, glass }\end{array}$ & $\begin{array}{l}\text { 安, 上, 宝, 冬, } \\
\text { 见, 买, 土, 头, } \\
\text { 田, 西, 又, 远, } \\
\text { 南, 成, 用, 国, } \\
\text { 她, 雨, 的, 走, } \\
\text { 打, 木, 草, 笔, } \\
\text { 鸟, 回,车, 爸, 几, } \\
\text { 路, 个, 手, 本, } \\
\text { 哭, 朋, 天 }\end{array}$ \\
\hline Word list 2 & 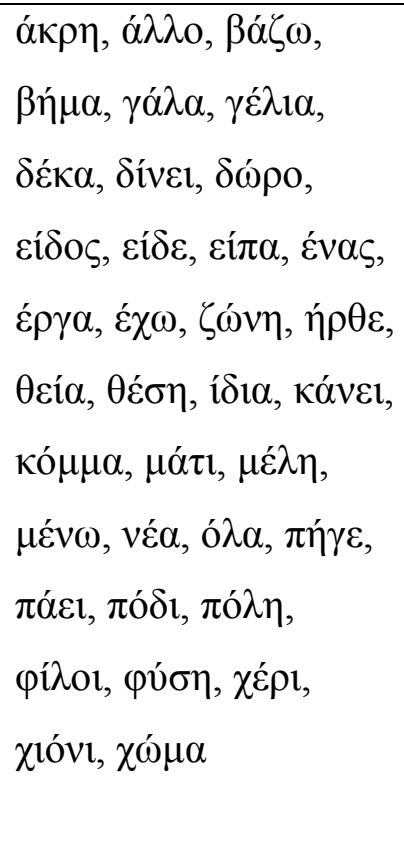 & $\begin{array}{l}\text { 안, 차, 나, 혀, 소, 쥐, } \\
\text { 음, 알, 울, 밥, 셈, 탓, } \\
\text { 돌, 빵, 논, 덕, 벌, 삽, } \\
\text { 해, 새, 개, 피, 파, 매, } \\
\text { 재, 토, 패, 윳, 폼, 톱, } \\
\text { 붓, 숯, 둑, 국, 약, 형 }\end{array}$ & $\begin{array}{l}\text { buy, eat, may, sea, } \\
\text { show, car, hat, dog, } \\
\text { end, fun, has, top, } \\
\text { lot, set, sun, bike, } \\
\text { bird, call, cook, } \\
\text { coat, door, feet, } \\
\text { keep, seen, snow, } \\
\text { tell, catch, large, } \\
\text { mouse, night, } \\
\text { while, box, gold, } \\
\text { land, salt, } \\
\text { class }\end{array}$ & $\begin{array}{l}\text { 动, 春, 高, 门, } \\
\text { 石, 工, 山, 早, } \\
\text { 女, 好, 跑, 要, } \\
\text { 水, 看, 坐, 年, } \\
\text { 妈, 方, 心, 衣, } \\
\text { 红, 地, 他, 不, } \\
\text { 可,为, 云, 大, 过, } \\
\text { 毛, 名, 刀, 飞, } \\
\text { 白, 在, 比 }\end{array}$ \\
\hline
\end{tabular}




\section{Appendix B}

\begin{tabular}{|c|c|c|c|c|c|c|c|c|c|c|c|c|}
\hline \multirow[b]{2}{*}{ Measure } & \multicolumn{4}{|c|}{ Number words } & \multicolumn{4}{|c|}{ Word list 1} & \multicolumn{4}{|c|}{ Word list 2} \\
\hline & $\mathrm{M}$ & SD & $\min$ & $\max$ & $\mathrm{M}$ & SD & $\min$ & $\max$ & $\mathrm{M}$ & SD & $\min$ & $\max$ \\
\hline \multicolumn{13}{|l|}{ Greek } \\
\hline Number of letters & 3.8 & 1.0 & 3 & 5 & 4.1 & 0.6 & 3 & 5 & 4.1 & 0.5 & 3 & 5 \\
\hline Number of phonemes & 3.8 & 0.5 & 3 & 4 & 3.8 & 0.4 & 3 & 4 & 3.8 & 0.4 & 3 & 4 \\
\hline Number of syllables & 2.0 & 0.0 & 2 & 2 & 2.0 & 0.0 & 2 & 2 & 2.0 & 0.0 & 2 & 2 \\
\hline Printed frequency (children) & 5.5 & 0.4 & 5.1 & 6.0 & 5.2 & 0.5 & 4.6 & 6.5 & 5.3 & 0.4 & 4.4 & 6.1 \\
\hline Printed frequency (adult) & 5.6 & 0.5 & 5.2 & 6.3 & 5.1 & 0.7 & 3.9 & 6.5 & 5.0 & 0.6 & 3.7 & 6.0 \\
\hline \multicolumn{13}{|l|}{ Korean } \\
\hline Number of letters & 2.8 & 0.5 & 2 & 3 & 2.7 & 0.5 & 2 & 3 & 2.6 & 0.5 & 2 & 3 \\
\hline Number of phonemes & 2.8 & 0.5 & 2 & 3 & 2.4 & 0.5 & 2 & 3 & 2.4 & 0.5 & 2 & 3 \\
\hline Number of syllables & 1.0 & 0.0 & 1 & 1 & 1.0 & 0.0 & 1 & 1 & 1.0 & 0.0 & 1 & 1 \\
\hline \multicolumn{13}{|l|}{ Printed frequency (children) } \\
\hline Printed frequency (adult) & 6.1 & 0.8 & 4.8 & 6.6 & 5.1 & 0.5 & 3.9 & 6.1 & 5.6 & 0.8 & 3.2 & 6.8 \\
\hline \multicolumn{13}{|l|}{ English } \\
\hline Number of letters & 3.8 & 1.0 & 3 & 5 & 3.8 & 0.7 & 3 & 5 & 3.8 & 0.7 & 3 & 5 \\
\hline Number of phonemes & 3.0 & 0.8 & 2 & 4 & 3.0 & 0.5 & 2 & 4 & 3.0 & 0.5 & 2 & 4 \\
\hline Number of syllables & 1.0 & 0.0 & 1 & 1 & 1.0 & 0.0 & 1 & 1 & 1.0 & 0.0 & 1 & 1 \\
\hline Printed frequency (children) & 5.6 & 0.4 & 5.2 & 6.0 & 5.6 & 0.3 & 5.2 & 6.1 & 5.6 & 0.3 & 5.3 & 6.1 \\
\hline Printed frequency (adult) & 5.7 & 0.4 & 5.3 & 5.8 & 5.1 & 0.5 & 4.1 & 6.4 & 5.2 & 0.5 & 4.0 & 6.4 \\
\hline \multicolumn{13}{|l|}{ Chinese } \\
\hline Number of strokes & 3.3 & 1.0 & 2 & 4 & 5.9 & 2.4 & 2 & 13 & 5.3 & 2.2 & 2 & 11 \\
\hline Number of phonemes & 2.5 & 1.3 & 1 & 4 & 2.7 & 0.7 & 1 & 4 & 2.7 & 0.6 & 1 & 4 \\
\hline Number of syllables & 1.0 & 0.0 & 1 & 1 & 1.0 & 0.0 & 1 & 1 & 1.0 & 0.0 & 1 & 1 \\
\hline Printed frequency (children) & 6.2 & 0.3 & 5.8 & 6.5 & 6.0 & 0.5 & 5.0 & 7.6 & 6.1 & 0.5 & 4.9 & 6.9 \\
\hline Printed frequency (adult) & 6.0 & 0.3 & 5.7 & 6.2 & 5.9 & 0.6 & 5.1 & 7.7 & 6.1 & 0.5 & 5.0 & 7.0 \\
\hline
\end{tabular}

Note. Printed word frequencies are in the Zipf scale (Van Heuven et al., 2014). Greek: children's frequencies are based on the language arts textbooks for Grades 1-6; adult frequencies from the IPLR C corpus (Protopapas et al., 2012). Korean: adult frequencies are based on the Korean Corpus (National Institute of the Korean Language, 2005); children's frequencies are not available. English: children's frequencies are based on Children's Printed Word Database of words which appear in books for children in Grades 1-4 (Masterson, Stuart, Dixon, \& Lovejoy, 2010); adult frequencies from the MRC psycholinguistic database (Coltheart, 1981). Chinese: children frequencies are based on textbooks for Grades 1-6 (Zeng, 2000); adult frequencies from the CNCORPUS (Xiao, 2012). 
Table 1

Means and Standard Deviations for all Measures (Items per Second) in Each Language

\begin{tabular}{|c|c|c|c|c|c|c|c|c|c|c|c|c|}
\hline \multirow[b]{2}{*}{ Measures } & \multicolumn{3}{|c|}{ Greek } & \multicolumn{3}{|c|}{ Korean } & \multicolumn{3}{|c|}{ English } & \multicolumn{3}{|c|}{ Chinese } \\
\hline & $N$ & $M$ & $S D$ & $N$ & $M$ & $S D$ & $N$ & $M$ & $S D$ & $N$ & $M$ & $S D$ \\
\hline \multicolumn{13}{|l|}{ Discrete } \\
\hline Digits & 103 & 1.13 & .16 & 100 & 1.25 & .16 & 107 & 1.05 & .15 & 112 & 1.40 & .18 \\
\hline Words & 103 & .96 & .17 & 100 & 1.23 & .15 & 105 & .99 & .13 & 113 & 1.25 & .15 \\
\hline \multicolumn{13}{|l|}{ Serial } \\
\hline Digits & 103 & 1.91 & .34 & 100 & 1.97 & .42 & 107 & 1.70 & .39 & 113 & 2.36 & .41 \\
\hline Words & 103 & 1.40 & .40 & 99 & 1.64 & .31 & 107 & 1.59 & .39 & 113 & 1.88 & .33 \\
\hline
\end{tabular}

Note. Higher scores represent faster performance. 
Table 2

Discrete Naming Accuracy (\%) for Digits and Words in Each Language

\begin{tabular}{|c|c|c|c|c|c|c|c|c|}
\hline & \multicolumn{2}{|c|}{ Greek } & \multicolumn{2}{|c|}{ Korean } & \multicolumn{2}{|c|}{ English } & \multicolumn{2}{|c|}{ Chinese } \\
\hline & $M$ & $S D$ & $M$ & $S D$ & $M$ & $S D$ & $M$ & $S D$ \\
\hline Digits & 99.1 & 3.6 & 98.9 & 2.3 & 98.6 & 2.9 & 98.9 & 1.8 \\
\hline Words & 98.2 & 3.3 & 98.3 & 3.3 & 95.9 & 4.6 & 99.5 & 1.6 \\
\hline
\end{tabular}


Table 3

Correlations (Pearson's r) Among Tasks in Each Language

\begin{tabular}{|c|c|c|c|c|c|c|c|c|c|c|c|c|}
\hline & \multicolumn{3}{|c|}{ Greek } & \multicolumn{3}{|c|}{ Korean } & \multicolumn{3}{|c|}{ English } & \multicolumn{3}{|c|}{ Chinese } \\
\hline & $\mathrm{dWrd}$ & sDig & sWrd & $\mathrm{dWrd}$ & sDig & sWrd & $\mathrm{dWrd}$ & sDig & sWrd & $\mathrm{dWrd}$ & sDig & sWrd \\
\hline d-Digits & .82 & .48 & .48 & .84 & .36 & .43 & .63 & .34 & .20 & .77 & .37 & .38 \\
\hline d-Words & & .60 & .68 & & .34 & .48 & & .18 & .52 & & .31 & .37 \\
\hline s-Digits & & & .62 & & & .68 & & & .56 & & & .53 \\
\hline
\end{tabular}

Note. $\mathrm{d}=$ discrete $\mathrm{s}=$ serial $;$ Dig $=$ Digits; $\mathrm{Wrd}=$ Words. 
Table 4

Standardized Regression Coefficients (B), Associated Probabilities (p), and Adjusted $R^{2}$ for Multiple Regression Models Predicting Discrete and Serial Words in Each Language

\begin{tabular}{|c|c|c|c|c|c|c|c|c|c|c|c|c|}
\hline & \multicolumn{5}{|c|}{ DV: d-Words } & \multicolumn{7}{|c|}{ DV: s-Words } \\
\hline & \multicolumn{2}{|c|}{ s-Digits } & \multicolumn{2}{|c|}{ d-Digits } & \multirow{2}{*}{$\begin{array}{l}\text { adj. } \\
\quad R^{2}\end{array}$} & \multicolumn{2}{|c|}{ d-Words } & \multicolumn{2}{|c|}{ s-Digits } & \multicolumn{2}{|c|}{ d-Digits } & \multirow{2}{*}{$\begin{array}{r}\text { adj. } \\
\quad R^{2}\end{array}$} \\
\hline & $B$ & $p$ & $B$ & $p$ & & $B$ & $p$ & $B$ & $p$ & $B$ & $p$ & \\
\hline Greek & .264 & $<.001$ & .694 & $<.001$ & .724 & .693 & $<.001$ & .319 & $<.001$ & -.243 & .042 & .541 \\
\hline Korean & .055 & .351 & .819 & $<.001$ & .699 & .310 & .019 & .585 & $<.001$ & -.041 & .753 & .512 \\
\hline English & -.050 & .532 & .673 & $<.001$ & .421 & .605 & $<.001$ & .583 & $<.001$ & -.340 & $<.001$ & .531 \\
\hline Chinese & .004 & .947 & .774 & $<.001$ & .595 & .167 & .184 & .449 & $<.001$ & .084 & .515 & .312 \\
\hline
\end{tabular}

Note. $\mathrm{DV}=$ dependent variable; $\mathrm{d}=$ discrete; $\mathrm{s}=$ serial. 


\section{Figure Captions}

Figure 1. Top, unconstrained path models estimated separately for each language predicting discrete words from serial digits and discrete digits. Parameter estimates are arranged on a grid for Greek, Korean, Chinese, and English, clockwise from top left, as shown in the legend. Bottom, final multigroup path model with equality constraints applied across languages. Collapsed grid cells contain parameters constrained to be equal, retaining the spatial arrangement of the four languages.

Note. $\mathrm{d}=$ discrete; $\mathrm{s}=$ serial; $\mathrm{Wrd}=$ word reading; Dig = digit naming.

Figure 2. Top, unconstrained path models estimated separately for each language predicting serial words from discrete words, serial digits, and discrete digits. Parameter estimates are arranged on a grid for Greek, Korean, Chinese, and English, clockwise from top left, as shown in the legend. Bottom, final multigroup path model with equality constraints applied across languages. Collapsed grid cells contain parameters constrained to be equal, retaining the spatial arrangement of the four languages.

Note. $\mathrm{d}=$ discrete; $\mathrm{s}=$ serial; $\mathrm{Wrd}=$ word reading; Dig = digit naming. 

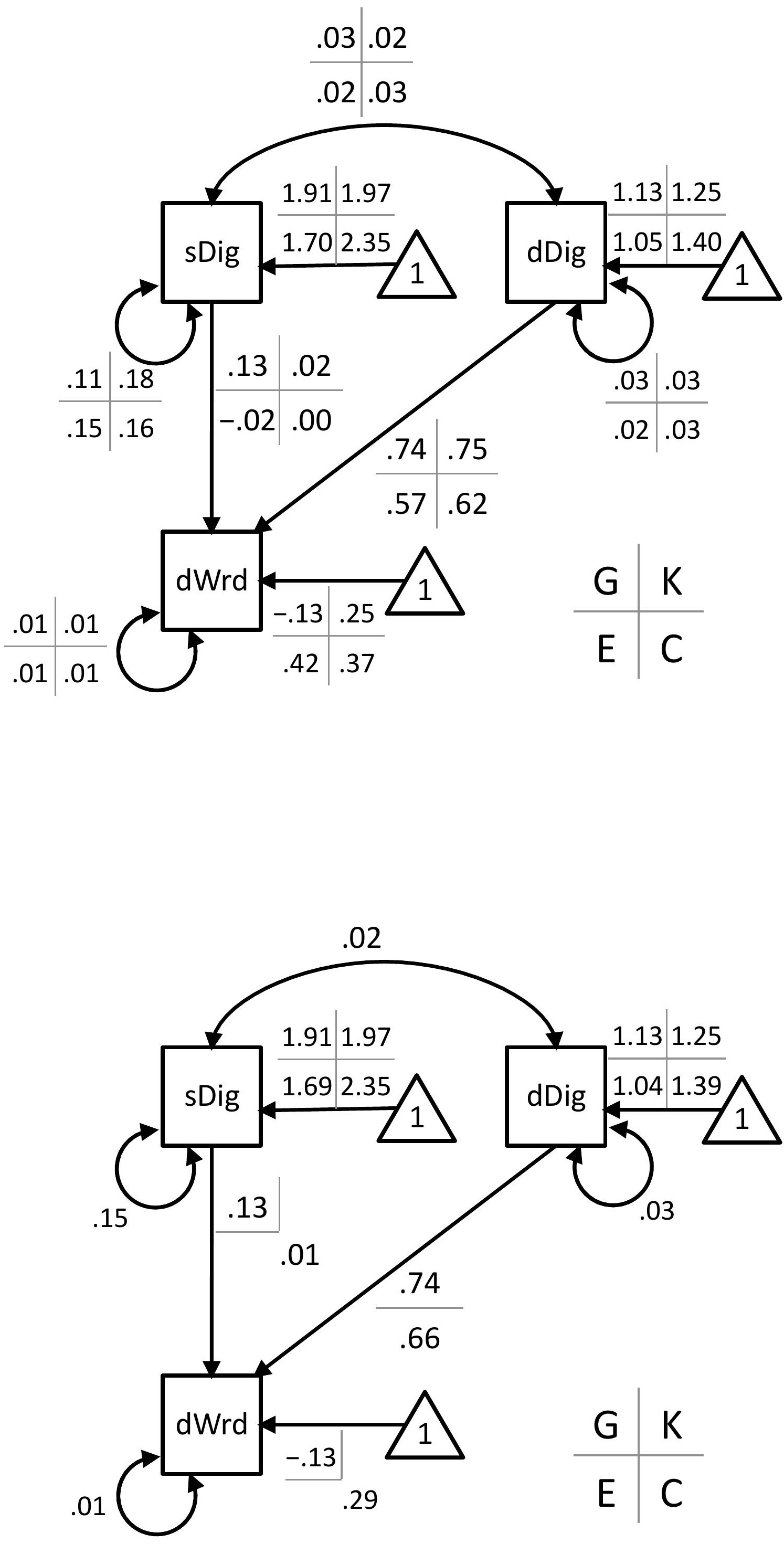


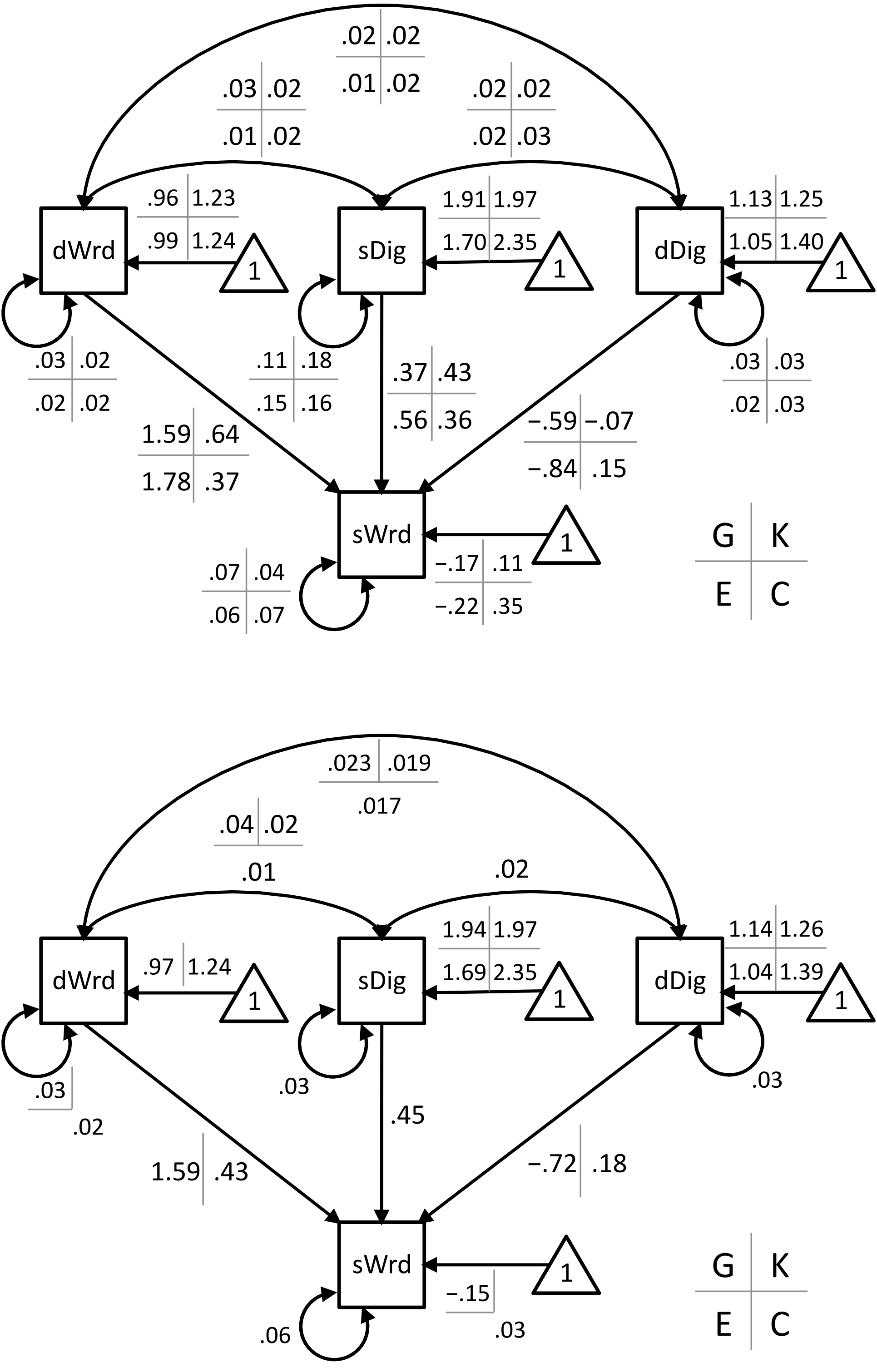


Is Processing of Symbols and Words Influenced by Writing System?

Evidence from Chinese, Korean, English, and Greek

\author{
Angeliki Altani and George K. Georgiou \\ University of Alberta \\ Ciping Deng \\ East China Normal University \\ Jeung-Ryeul Cho \\ Kyungnam University \\ Katerina Katopodi \\ National and Kapodistrian University of Athens \\ Wei Wei \\ Shanghai Normal University \\ Athanassios Protopapas* \\ National and Kapodistrian University of Athens and University of Oslo
}




\section{Figure S1}

Q-Q plots for individual accuracy in discrete digits (left) and words (right) in each language (rows); the horizontal dashed line at 33\% errors shows the outlier cutoff.

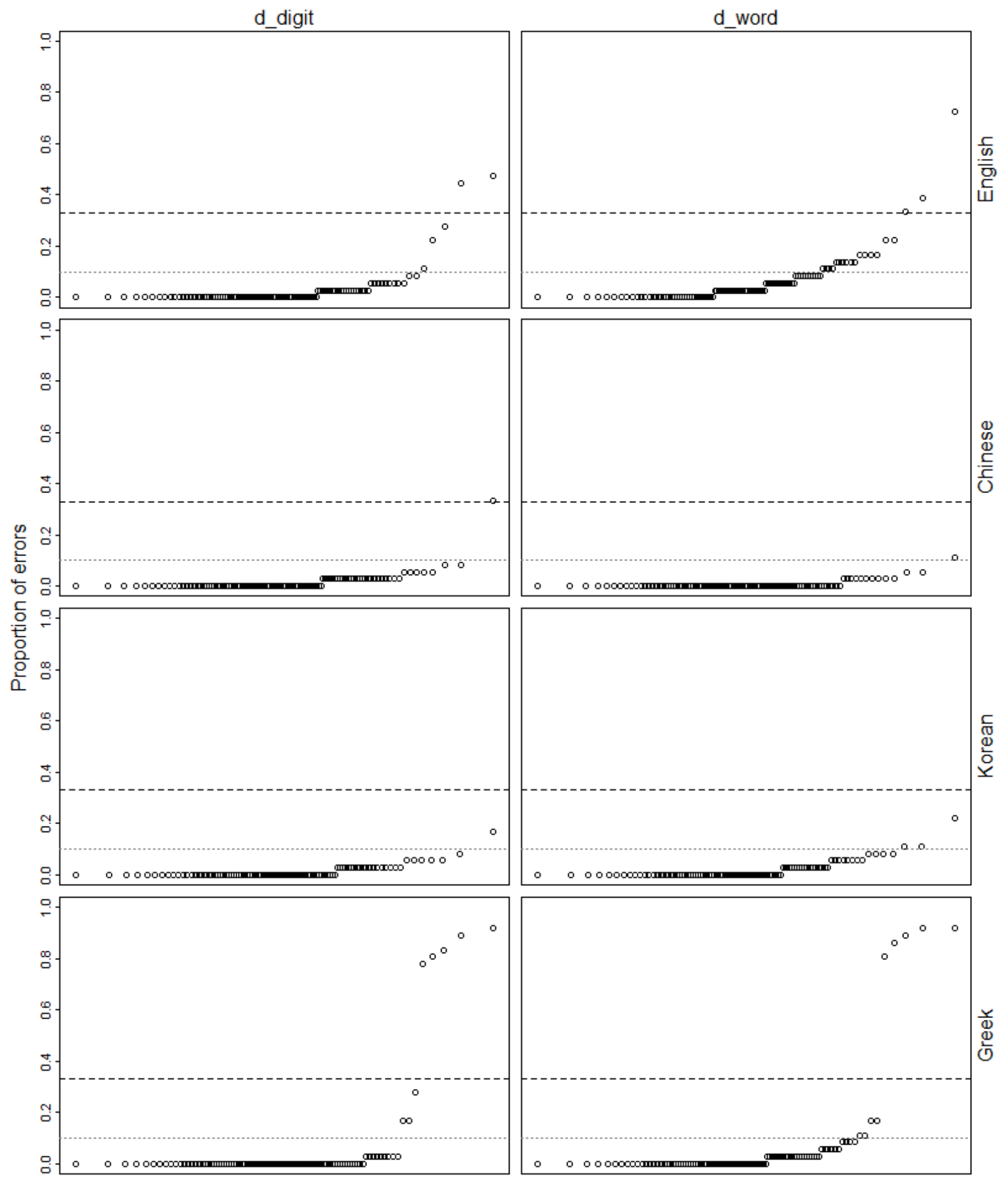




\section{Figure S2}

$Q-Q$ plots for individual reading and naming rate (items per second) in each task and each language (cleaned-up data set)
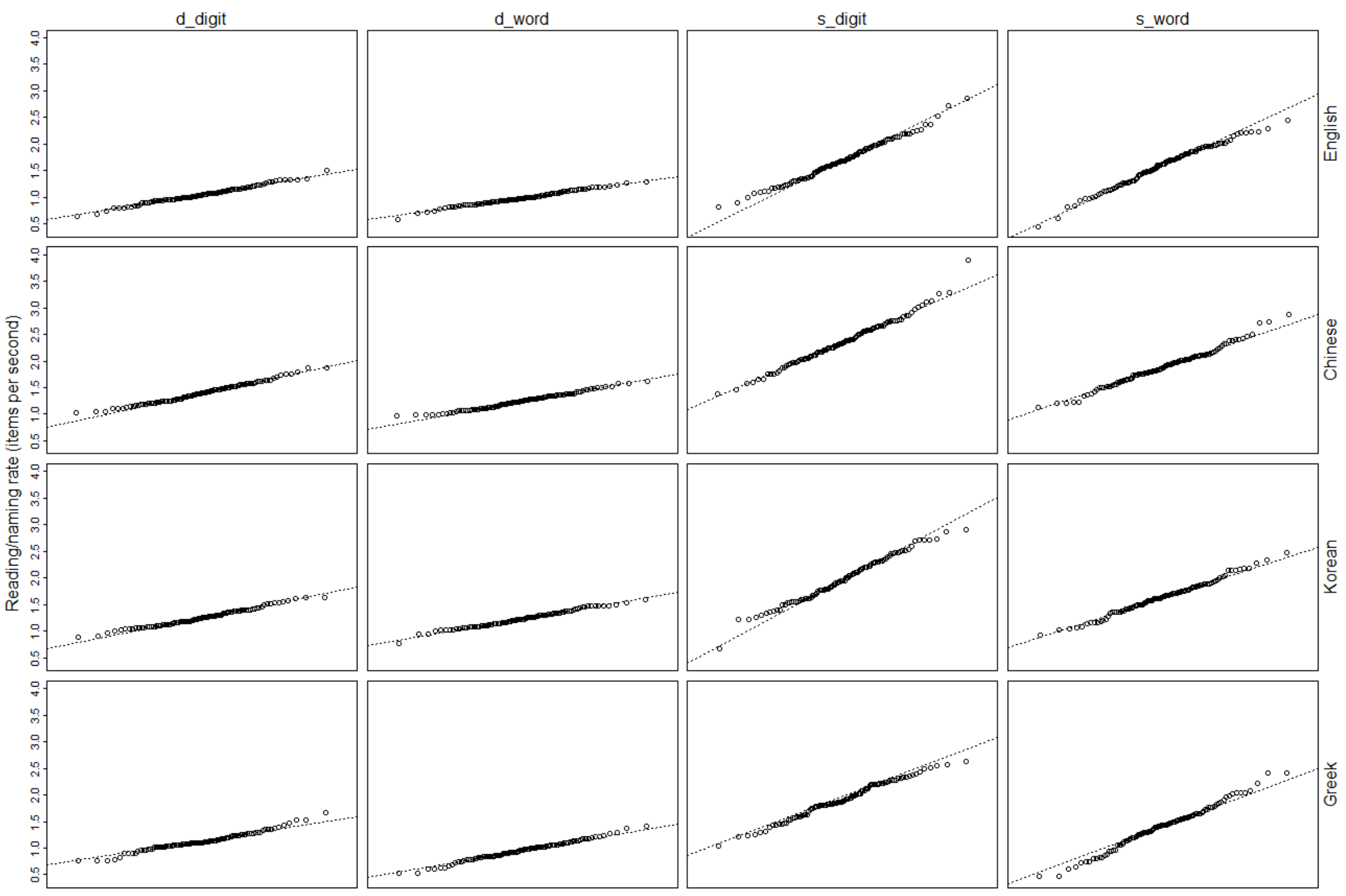
Table S1

Shapiro-Wilks tests of normality for each task and language

\begin{tabular}{|c|c|c|c|c|c|c|c|c|}
\hline & \multicolumn{2}{|c|}{ English } & \multicolumn{2}{|c|}{ Chinese } & \multicolumn{2}{|c|}{ Korean } & \multicolumn{2}{|c|}{ Greek } \\
\hline & $W$ & $p$ & $W$ & $p$ & $W$ & $p$ & $W$ & $p$ \\
\hline d-Digits & .992 & .775 & .987 & .327 & .986 & .385 & .971 & .024 \\
\hline d-Words & .991 & .749 & .985 & .241 & .989 & .609 & .992 & .831 \\
\hline s-Digits & .991 & .704 & .986 & .291 & .990 & .635 & .987 & .431 \\
\hline s-Words & .987 & .357 & .986 & .311 & .992 & .840 & .990 & .607 \\
\hline
\end{tabular}

Note. $\mathrm{d}=$ discrete; $\mathrm{s}=$ serial . 
Table S2

Estimated parameters for the unconstrained multi-group model predicting discrete words in each language

\begin{tabular}{|c|c|c|c|c|c|c|c|c|c|c|c|c|c|c|c|}
\hline & \multirow[b]{2}{*}{ Parameter type } & \multirow[b]{2}{*}{ to } & \multirow[b]{2}{*}{ from } & \multicolumn{3}{|c|}{ Chinese } & \multicolumn{3}{|c|}{ English } & \multicolumn{3}{|c|}{ Greek } & \multicolumn{3}{|c|}{ Korean } \\
\hline & & & & Est. & $S E$ & $p$ & Est. & $S E$ & $p$ & Est. & $S E$ & $p$ & Est. & $S E$ & $p$ \\
\hline 1 & Regression coefficient & $\mathrm{dWrd}$ & sDig & 0.002 & 0.023 & .947 & -0.016 & 0.025 & .524 & 0.135 & 0.030 & $<.001$ & 0.019 & 0.020 & .341 \\
\hline 2 & Regression coefficient & $\mathrm{dWrd}$ & dDig & 0.622 & 0.052 & $<.001$ & 0.568 & 0.066 & $<.001$ & 0.738 & 0.062 & $<.001$ & 0.755 & 0.054 & $<.001$ \\
\hline 3 & Intercept & dWrd & 1 & 0.370 & 0.073 & $<.001$ & 0.419 & 0.068 & $<.001$ & -0.134 & 0.066 & .043 & 0.247 & 0.065 & $<.001$ \\
\hline 4 & Residual variance & dWrd & $\mathrm{dWrd}$ & 0.008 & 0.001 & $<.001$ & 0.009 & 0.001 & $<.001$ & 0.008 & 0.001 & $<.001$ & 0.007 & 0.001 & $<.001$ \\
\hline 5 & Variance & sDig & sDig & 0.165 & 0.022 & $<.001$ & 0.152 & 0.021 & $<.001$ & 0.112 & 0.016 & $<.001$ & 0.179 & 0.025 & $<.001$ \\
\hline 6 & Variance & dDig & dDig & 0.033 & 0.004 & $<.001$ & 0.022 & 0.003 & $<.001$ & 0.026 & 0.004 & $<.001$ & 0.026 & 0.004 & $<.001$ \\
\hline 7 & Covariance & sDig & dDig & 0.028 & 0.007 & $<.001$ & 0.020 & 0.006 & .001 & 0.026 & 0.006 & $<.001$ & 0.024 & 0.007 & .001 \\
\hline 8 & Observed mean & sDig & 1 & 2.350 & 0.038 & $<.001$ & 1.700 & 0.038 & $<.001$ & 1.913 & 0.033 & $<.001$ & 1.972 & 0.042 & $<.001$ \\
\hline 9 & Observed mean & $\mathrm{dDig}$ & 1 & 1.398 & 0.017 & $<.001$ & 1.047 & 0.015 & $<.001$ & 1.128 & 0.016 & $<.001$ & 1.254 & 0.016 & $<.001$ \\
\hline
\end{tabular}

Note. Est. = Parameter estimate; $\mathrm{d}=$ discrete; $\mathrm{s}=$ serial; $\mathrm{Wrd}=$ word reading; Dig = digit naming. 
Table S3

Estimated parameters for the constrained multi-group model predicting discrete words in all languages

\begin{tabular}{|c|c|c|c|c|c|c|c|c|c|c|}
\hline & Parameter type & & Lang & age & & to & from & Est. & $\overline{S E}$ & $p$ \\
\hline 1 & Regression coefficient & Chinese & English & & Korean & $\mathrm{dWrd}$ & sDig & 0.010 & 0.013 & .408 \\
\hline 2 & Regression coefficient & & & Greek & & $\mathrm{dWrd}$ & sDig & 0.135 & 0.027 & $<.001$ \\
\hline 3 & Regression coefficient & Chinese & English & & & $\mathrm{dWrd}$ & dDig & 0.660 & 0.027 & $<.001$ \\
\hline 4 & Regression coefficient & & & Greek & Korean & $\mathrm{dWrd}$ & dDig & 0.738 & 0.026 & $<.001$ \\
\hline 5 & Intercept & Chinese & English & & Korean & $\mathrm{dWrd}$ & 1 & 0.287 & 0.028 & $<.001$ \\
\hline 6 & Intercept & & & Greek & & $\mathrm{dWrd}$ & 1 & -0.134 & 0.055 & .014 \\
\hline 7 & Residual variance & Chinese & English & Greek & Korean & $\mathrm{dWrd}$ & dWrd & 0.008 & 0.001 & $<.001$ \\
\hline 8 & Variance & Chinese & English & Greek & Korean & sDig & sDig & 0.152 & 0.010 & $<.001$ \\
\hline 9 & Variance & Chinese & English & Greek & Korean & dDig & dDig & 0.027 & 0.002 & $<.001$ \\
\hline 10 & Covariance & Chinese & English & Greek & Korean & sDig & dDig & 0.025 & 0.003 & $<.001$ \\
\hline 11 & Observed mean & Chinese & & & & sDig & 1 & 2.350 & 0.037 & $<.001$ \\
\hline 12 & Observed mean & Chinese & & & & dDig & 1 & 1.398 & 0.016 & $<.001$ \\
\hline 13 & Observed mean & & English & & & sDig & 1 & 1.700 & 0.038 & $<.001$ \\
\hline 14 & Observed mean & & English & & & dDig & 1 & 1.047 & 0.016 & $<.001$ \\
\hline 15 & Observed mean & & & Greek & & sDig & 1 & 1.913 & 0.038 & $<.001$ \\
\hline 16 & Observed mean & & & Greek & & dDig & 1 & 1.128 & 0.016 & $<.001$ \\
\hline 17 & Observed mean & & & & Korean & sDig & 1 & 1.972 & 0.039 & $<.001$ \\
\hline 18 & Observed mean & & & & Korean & dDig & 1 & 1.254 & 0.016 & $<.001$ \\
\hline
\end{tabular}

Note . Est. $=$ Parameter estimate $; \mathrm{d}=$ discrete $\mathrm{s}=$ serial; $\mathrm{Wrd}=$ word reading; Dig $=$ digit naming. 
Table S4

Estimated parameters for the unconstrained multi-group model predicting serial words in each language

\begin{tabular}{|c|c|c|c|c|c|c|c|c|c|c|c|c|c|c|c|}
\hline & \multirow[b]{2}{*}{ Parameter type } & \multirow[b]{2}{*}{ to } & \multirow[b]{2}{*}{ from } & \multicolumn{3}{|c|}{ Chinese } & \multicolumn{3}{|c|}{ English } & \multicolumn{3}{|c|}{ Greek } & \multicolumn{3}{|c|}{ Korean } \\
\hline & & & & Est. & $S E$ & $p$ & Est. & $S E$ & $p$ & Est. & $S E$ & $p$ & Est. & $S E$ & $p$ \\
\hline 1 & Regression coefficient & sWrd & $\mathrm{dWrd}$ & 0.375 & 0.275 & .173 & 1.782 & 0.257 & $<.001$ & 1.594 & 0.291 & $<.001$ & 0.640 & 0.263 & .015 \\
\hline 2 & Regression coefficient & sWrd & sDig & 0.362 & 0.067 & $<.001$ & 0.556 & 0.067 & $<.001$ & 0.374 & 0.097 & $<.001$ & 0.427 & 0.054 & $<.001$ \\
\hline 3 & Regression coefficient & sWrd & dDig & 0.152 & 0.228 & .506 & -0.845 & 0.228 & $<.001$ & -0.593 & 0.282 & .036 & -0.078 & 0.243 & .747 \\
\hline 4 & Intercept & sWrd & 1 & 0.354 & 0.235 & .132 & -0.223 & 0.210 & .289 & -0.167 & 0.199 & .403 & 0.108 & 0.184 & .556 \\
\hline 5 & Residual variance & sWrd & sWrd & 0.072 & 0.010 & $<.001$ & 0.063 & 0.009 & $<.001$ & 0.069 & 0.010 & $<.001$ & 0.045 & 0.006 & $<.001$ \\
\hline 6 & Variance & $\mathrm{dWrd}$ & dWrd & 0.021 & 0.003 & $<.001$ & 0.016 & 0.002 & $<.001$ & 0.029 & 0.004 & $<.001$ & 0.022 & 0.003 & $<.001$ \\
\hline 7 & Variance & sDig & sDig & 0.165 & 0.022 & $<.001$ & 0.152 & 0.021 & $<.001$ & 0.112 & 0.016 & $<.001$ & 0.178 & 0.025 & $<.001$ \\
\hline 8 & Variance & dDig & dDig & 0.033 & 0.004 & $<.001$ & 0.022 & 0.003 & $<.001$ & 0.026 & 0.004 & $<.001$ & 0.026 & 0.004 & $<.001$ \\
\hline 9 & Covariance & $\mathrm{dWrd}$ & sDig & 0.018 & 0.006 & .003 & 0.009 & 0.005 & .065 & 0.034 & 0.007 & $<.001$ & 0.022 & 0.007 & .001 \\
\hline 10 & Covariance & $\mathrm{dWrd}$ & dDig & 0.021 & 0.003 & $<.001$ & 0.012 & 0.002 & $<.001$ & 0.023 & 0.004 & $<.001$ & 0.020 & 0.003 & $<.001$ \\
\hline 11 & Covariance & sDig & dDig & 0.028 & 0.007 & $<.001$ & 0.020 & 0.006 & .001 & 0.026 & 0.006 & $<.001$ & 0.024 & 0.007 & .001 \\
\hline 12 & Observed mean & dWrd & 1 & 1.244 & 0.014 & $<.001$ & 0.986 & 0.012 & $<.001$ & 0.955 & 0.017 & $<.001$ & 1.232 & 0.015 & $<.001$ \\
\hline 13 & Observed mean & sDig & 1 & 2.350 & 0.038 & $<.001$ & 1.700 & 0.038 & $<.001$ & 1.913 & 0.033 & $<.001$ & 1.967 & 0.042 & $<.001$ \\
\hline 14 & Observed mean & dDig & 1 & 1.398 & 0.017 & $<.001$ & 1.047 & 0.015 & $<.001$ & 1.128 & 0.016 & $<.001$ & 1.254 & 0.016 & $<.001$ \\
\hline
\end{tabular}

Note. Est. $=$ Parameter estimate $\mathrm{d}=$ discrete $\mathrm{s}=$ serial; $\mathrm{Wrd}=$ word reading; Dig $=$ digit naming. 
Table S5

Estimated parameters for the constrained multi-group model predicting serial words in all languages

\begin{tabular}{|c|c|c|c|c|c|c|c|c|c|c|}
\hline & Parameter type & & Languc & & & to & from & Est. & $S E$ & $p$ \\
\hline 1 & Regression coefficient & Chinese & & & Korean & sWrd & $\mathrm{dWrd}$ & 0.429 & 0.164 & .009 \\
\hline 2 & Regression coefficient & & English & Greek & & sWrd & $\mathrm{dWrd}$ & 1.585 & 0.173 & $<.001$ \\
\hline 3 & Regression coefficient & Chinese & English & Greek & Korean & sWrd & sDig & 0.446 & 0.034 & $<.001$ \\
\hline 4 & Regression coefficient & Chinese & & & Korean & sWrd & dDig & 0.178 & 0.148 & .230 \\
\hline 5 & Regression coefficient & & English & Greek & & sWrd & dDig & -0.718 & 0.166 & $<.001$ \\
\hline 6 & Intercept & Chinese & English & & Korean & sWrd & 1 & 0.030 & 0.099 & .763 \\
\hline 7 & Intercept & & & Greek & & sWrd & 1 & -0.154 & 0.107 & .151 \\
\hline 8 & Residual variance & Chinese & English & Greek & Korean & sWrd & sWrd & 0.064 & 0.004 & $<.001$ \\
\hline 9 & Residual variance & Chinese & English & & Korean & $\mathrm{dWrd}$ & $\mathrm{dWrd}$ & 0.020 & 0.002 & $<.001$ \\
\hline 10 & Residual variance & & & Greek & & dWrd & $\mathrm{dWrd}$ & 0.030 & 0.003 & $<.001$ \\
\hline 20 & Residual variance & Chinese & English & Greek & Korean & sDig & sDig & 0.151 & 0.010 & $<.001$ \\
\hline 12 & Residual variance & Chinese & English & Greek & Korean & dDig & dDig & 0.027 & 0.002 & $<.001$ \\
\hline 15 & Covariance & Chinese & English & Greek & Korean & sDig & dDig & 0.024 & 0.003 & $<.001$ \\
\hline 14 & Covariance & Chinese & English & & & dWrd & sDig & 0.014 & 0.003 & $<.001$ \\
\hline 11 & Covariance & & & Greek & & $\mathrm{dWrd}$ & sDig & 0.038 & 0.005 & $<.001$ \\
\hline 21 & Covariance & & & & Korean & dWrd & sDig & 0.020 & 0.003 & $<.001$ \\
\hline 23 & Covariance & Chinese & English & & & dWrd & dDig & 0.017 & 0.002 & $<.001$ \\
\hline 13 & Covariance & & & Greek & & dWrd & dDig & 0.023 & 0.002 & $<.001$ \\
\hline 22 & Covariance & & & & Korean & $\mathrm{dWrd}$ & dDig & 0.019 & 0.002 & $<.001$ \\
\hline 24 & Observed mean & Chinese & & & Korean & $\mathrm{dWrd}$ & 1 & 1.238 & 0.010 & $<.001$ \\
\hline 16 & Observed mean & & English & Greek & & dWrd & 1 & 0.974 & 0.011 & $<.001$ \\
\hline 19 & Observed mean & Chinese & & & & sDig & 1 & 2.346 & 0.036 & $<.001$ \\
\hline 17 & Observed mean & Chinese & & & & dDig & 1 & 1.393 & 0.013 & $<.001$ \\
\hline 18 & Observed mean & & English & & & sDig & 1 & 1.691 & 0.038 & $<.001$ \\
\hline 25 & Observed mean & & English & & & dDig & 1 & 1.037 & 0.014 & $<.001$ \\
\hline 26 & Observed mean & & & Greek & & sDig & 1 & 1.937 & 0.034 & $<.001$ \\
\hline 27 & Observed mean & & & Greek & & dDig & 1 & 1.142 & 0.013 & $<.001$ \\
\hline 28 & Observed mean & & & & Korean & sDig & 1 & 1.974 & 0.038 & $<.001$ \\
\hline 29 & Observed mean & & & & Korean & dDig & 1 & 1.260 & 0.013 & $<.001$ \\
\hline
\end{tabular}

Note . Est. $=$ Parameter estimate $; \mathrm{d}=$ discrete $\mathrm{s}=$ serial; Wrd $=$ word reading; Dig = digit naming. 